\title{
The Impact of the Transition from Analog to Digital Process Display Gauges on Human Error and Safety in the Chemical Industry
}

Allen J. Thacker

Follow this and additional works at: https://researchrepository.wvu.edu/etd

Part of the Educational Technology Commons, and the Vocational Education Commons

\section{Recommended Citation}

Thacker, Allen J., "The Impact of the Transition from Analog to Digital Process Display Gauges on Human Error and Safety in the Chemical Industry" (2002). Graduate Theses, Dissertations, and Problem Reports. 8082.

https://researchrepository.wvu.edu/etd/8082

This Dissertation is protected by copyright and/or related rights. It has been brought to you by the The Research Repository @ WVU with permission from the rights-holder(s). You are free to use this Dissertation in any way that is permitted by the copyright and related rights legislation that applies to your use. For other uses you must obtain permission from the rights-holder(s) directly, unless additional rights are indicated by a Creative Commons license in the record and/ or on the work itself. This Dissertation has been accepted for inclusion in WVU Graduate Theses, Dissertations, and Problem Reports collection by an authorized administrator of The Research Repository @ WVU.

For more information, please contact researchrepository@mail.wvu.edu. 


\title{
The Impact of the Transition from Analog to Digital Process Display Gauges on Human Error and Safety in the Chemical Industry
}

\author{
By
}

Allen J. Thacker

DISSERTATION

Submitted to the College of Human Resources and Education

at

\begin{abstract}
West Virginia University
In partial fulfillment of requirements for

The Degree of Doctor of Education
\end{abstract}

\author{
Edward Pytlik, Chair \\ John G. Wells \\ Harold Carl \\ Michael Klishis \\ Michael Brantmayer
}

Technology Education

Morgantown, West Virginia

2002

Key Words: Analog and Digital Displays, Human Factors, Safety, Control Rooms 


\begin{abstract}
The Impact of the Transition from Analog to Digital Process Display Gauges on Human Error and Safety in the Chemical Industry
\end{abstract}

Allen J. Thacker

The use of new technological instruments in the work place has enabled operators to control processes and product development to tolerances that were unachievable in past decades. The chemical industry has exhibited rapid growth in the implementation of control monitoring instruments such as analog and digital display gauges as well as the software applications that provide the flexibility to successfully integrate the technology into the chemical manufacturing processes. This research was designed to examine the effects of the transition from analog displays to digital displays in the chemical industry. The results of the research provide benefits to chemical manufacturers and their safety programs. The significant findings in this research provided evidence that the continuing transition from digital to analog display gauges has made a negative impact on the safety incidence rate. These findings suggested that chemical plant operators, while being required to complete more tasks in the same amount of time, exhibited various difficulties in working with digital display gauges. These suggested difficulties manifested themselves in the increased number of reported "Human Error" incident events. 


\section{Acknowledgements}

I will attempt to acknowledge those who have given me encouragement over the past 5 years in this quest.

First and foremost is my family. To my mother Anna Mary Thacker I can say nothing that would adequately communicate my deepest appreciation and love; for that love, affection, and encouragement as only a parent knows I can never repay. To my wife Jan Thacker and my children Erin and Kris who endured many late nights while waiting for me to arrive safely home after class and providing the constant encouragement without which it would not have been possible to complete this work thank you and all my love to you.

Second, to my committee, it has been a pleasure to be regarded as a peer in academia. Without your help and support I would have probably given up. I will always have fond memories of the hard work you put me through. You gentlemen who were my instructors can never know what pleasure and excitement it was to me to learn new things ... I will continue.

I also owe a great debt of gratitude to the following companies:

Apex Engineering and the staff for planting the original seed for this work and giving me the time and contributing to the resources in the early stages of this endeavor. Thank you.

Simonton Windows' administration and staff for their support, forward thinking, and willingness to provide opportunities without which this endeavor would have not survived the second and third year. It is my fondest hope that someday I have the opportunity return this great favor to a truly world class company.

You folks are special and thanks to you all.

Finally I would like to express my thanks and gratitude to the facilities that permitted me to examine their event records which provided the basis for this research and analysis.

I would like to dedicate this work to my late father O.K. (Pete) Thacker. In every sense I wish you were here to share in this accomplishment. 


\section{TABLE OF CONTENTS}

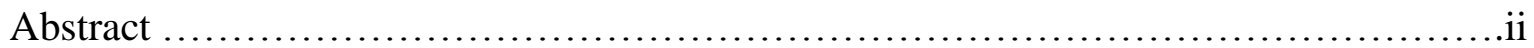

Acknowledgements...........................................................

List of Tables...............................................................

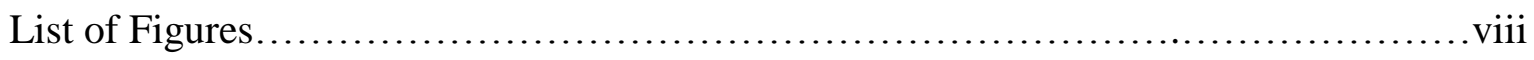

CHAPTER I.............................................................

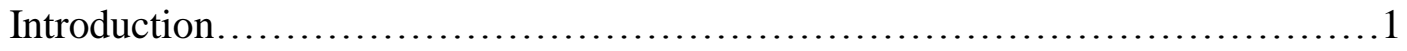

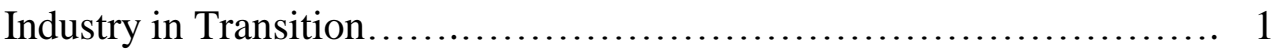

Emerging Industry Processes............................. 3

Modern Process Development.............................. 6

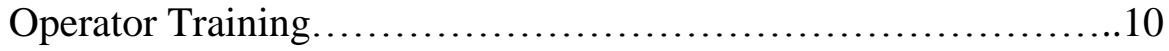

Current Statistics..........................................11

Problem Statement.............................................. 12

Purpose of Research........................................... 13

Research Hypothesis............................................ 13

Assumptions.....................................................13

Limitations.................................................. 14

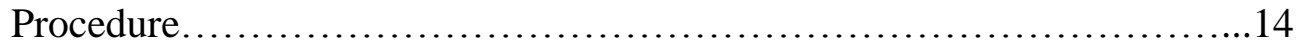

Definition of Terms............................................ 16

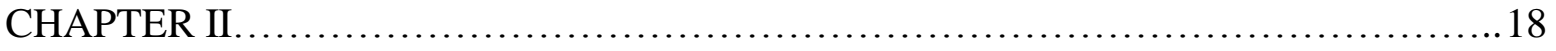

Review of Literature.................................................... 18

Introduction.................................................... 18 
Influence and Developments of Industrial Process Displays............. 18

Regulatory Agencies...........................................20

Occupational Safety and Health Administration ................. 20

United States Environmental Protection agency.................21

Data Collection.................................................23

Decision Making Processes and Safety.................................. 25

Prior Research..................................................25

Training Approaches.......................................... 28

Previous Human Factors Research.................................. 28

Industrial Training ............................................ 29

CHAPTER III............................................................... 32

Methodology........................................................ 32

Statement of Problem............................................ 32

Research Hypothesis.......................................... 32

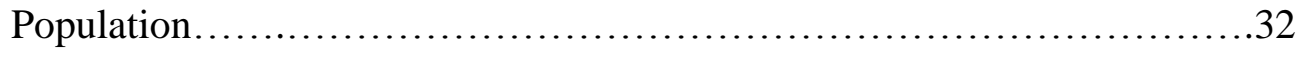

Procedures.................................................33

Analysis Format......................................... 37

Summary...................................................

CHAPTER IV ......................................................... 39

Analysis of Data..................................................... 39

Introduction..........................................................

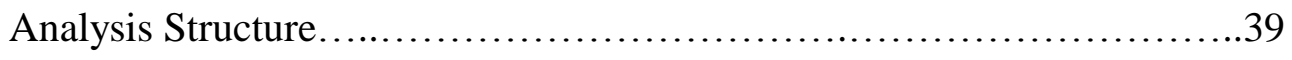

Analysis of Data..................................................40 
Events Summary.

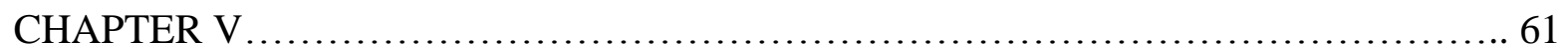

Summary, Findings, Conclusions, and Recommendations.....................61

Problem Statement............................................61

Summary.....................................................61

Statistical Observations......................................61

Data Review..............................................63

Analog and Digital Displays.................................64

Man-hours ..................................................65

Total Events on Record.....................................66

Total Human Error Events...................................66

Trends.................................................67

Findings and Conclusions......................................6 69

Concluding Comments/Observations.........................71

Training Assessment Methods .................................... 72

Recommendations for Further Research ............................73

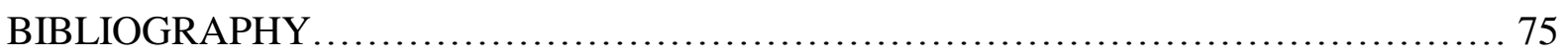

APPENDIX A: Analog/Digital Instrumentation Display Example...............80

Analog/Digital Display Gauge Layout.................................80

APPENDIX B: Data Gathering........................................ 81

Data Collection Form............................................. 82 


\section{LIST OF TABLES}

Table 1 Combined Group Data.......................................... 41

Table 2 Group A Data................................................. 47

Table $3 \quad$ Group B Data.................................................... 50

Table 4 Group A Incidence Data.........................................57

Table 5 Group B Incidence Data.......................................59

Table 6 Analysis of Variance for Analog Incidence Rates and

Combined Incidence Rate..........................................62

Table 7 Analysis of Variance for Digital Incidence Rates and

Combined Incidence Rate......................................... 63 


\section{LIST OF FIGURES}

Figure 1 Combined Incidence Rates Relationship to

Total Man-hours/Total Human Errors......................... 44

Figure 2 Combined Incidents by Cause Codes..............................45

Figure 3 Combined Analog and Digital Incidents related to

Total Human Error Event and Man-hours..................... 46

Figure 4 Group "A” OSHA Recordable Events Comparison with

Total Human Error Events.................................48

Figure 5 Group “A” Analog/Digital Incident Comparison to

Man-hours Worked.........................................49

Figure 6 Group "B” OSHA Recordable Incidents Compared to

Total Human Error Events..............................51

Figure 7 Group "B” Analog/Digital Incident Comparison to

Man-hours Worked....................................52

Figure 8 Group "A” Analog/Digital Incidents versus

Total Incidents Reviewed...................................53

Figure 9 Group "B" Analog/Digital Incidents versus

Total Incidents Reviewed..................................54

Figure 10 Group “A” Analog/digital Incidence Rate/Man-hour Comparison.........55

Figure 11 Group “B” Analog/Digital Incidence Rate/Man-hour Comparison........56 
Figure 12 Summary Comparison of Bureau of Labor Statistics (BLS)

Data and Group "A" Data...................................58

Figure 13 Summary Comparison of Bureau of Labor Statistics (BLS)

Data and Group "B" Data.................................60

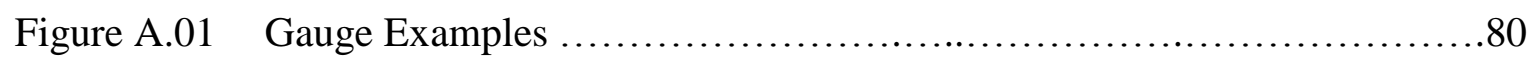

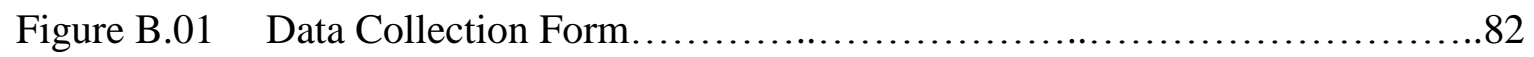




\section{Chapter I}

Introduction

\section{Industry in Transition}

The measurement of quantities relating to volumes, areas, distance, time, rate of change, and time and space has concerned man through the millennia. The ancients were preoccupied with the passage of time and developed various devices to calculate the time of day, month, and year for both religious and agrarian purposes. The ability to measure time provided a progressive reference "location" to past events and future events. Static measures such as weight, volume, and distance were developed as it became necessary to understand and use comparisons with known and unknown quantities. The ability to consistently compare against known standards helped in determining the value of artifacts and material substances or information about the condition of something for religious, commercial, and/or strategic purposes. Information, and the ability to interpret it correctly and consistently, was considered to be a valuable strategic commodity in all aspects of life. Those persons who could provide this information were highly regarded within their respective communities even though they were not immune to error in their interpretations.

In modern times, the "human operator" or "system interpreter" (human system interface) has now become an increasingly weaker link in the process system. New technology often fails to deliver the promised benefits, and may instead introduce new demands and complexities into an already exacting field of practice. In order to cope with these new conditions, people often adapt either the technology or their way of using it in ways not anticipated by designers (Roth, Bennett, \& Woods, 1987; Cook, Woods, \& Howie, 1990; 
Hutchins, 1990). Technological artifacts, or tools, both shape user strategies and are shaped by their users.

In today's chemical industry, system measurement and data collection functions influence many characteristics critical to the industrial process and environment. These characteristics include but were not limited to the measurement of substances with reference to temperatures, pressures, volumes, and flow. All of these measures were normally calibrated to an industry standard or a developed process parameter. Regardless of how complicated the control process was, the objective remains the same as it was in ancient times; correctness, consistency, and economy of resources. Within modern processes, the economy of resources had been expanded to include process safety and environmental concerns.

As the risks to the process and environment increased, the need for accurate data interpretation and response to these conditions also increased. With each technological advance, system information and interpretation became complicated to the point where response times for human interaction/decision opportunities require increasingly narrower parameters for safe and predictable operations. A good "human-system interface" was required in order for processes to be reliable, repeatable, and safe. Proper training had always been a corollary to good human-system interface design in system processes to reduce the impact of "human error".

This study provided insight into technological influences and developments of "instrumentation processes and displays" during the last 20 years within the chemical industry. The focus of this study was to review and assess existing incident data and determine the impact that instrumentation processes and display format changes have had on 
human error. Anecdotal information discussed the nature of the effects that human errors, caused by display formats, had on the chemical industry in the areas of process safety, system training, government mandated regulations, and on other legislative rule-making bodies. Tullis (1980) provided a basis for this research question with an observation suggesting that frequent training may provide operators with the necessary skills and abilities to overcome deficiencies/decrements in proper digital display responses as compared to proper analog display responses.

\section{$\underline{\text { Emerging Industry Processes }}$}

The history of tools can be interpreted as a history of amplification, first of muscle power (e.g., the lever or the pulley), then of perception (e.g., microscopes and telescopes), and then of regulation and control (e.g., automatic controllers and servomechanisms). Before the 1950s, tools were primarily designed to facilitate physical or mechanical work.

Developments in computing technology had made it possible to develop tools for cognitive or mental work. For years many organizations have experienced difficulties in turning technological developments into systems that actually improved performance in the target field (e.g., space, air traffic control, chemical plant control rooms, communication network management, ground satellite control stations) (Hollenagel, Cacciabue, 1999).

Information systems prior to the advent of electrical/pneumatic sensing devices relied heavily on employees/operators visually reading gauges, charts, and/or physically measuring various process levels. Typically the gathered data was further processed and/or archived for future use via manual operations. The development of human-machine systems as outlined by Kragt, (1983) was briefly described by the three following characteristic stages: 
- Manual Control was the first stage where simple physical measurements (pressures, temperatures) were displayed directly, according to the "one sensor - one indicator" principle. Initially, control and maneuvering was done locally, with direct reading of instruments and manipulation of single components (valves and switches). Later, measurements were gradually collected on local instrument boards for the single machine or group of machines, but equipment was still manipulated directly. Operators were used as if they were just another piece of equipment to support the functions of the machine in a closed loop. The machine was primarily an amplifier of human physical strength and precision, and tasks mainly consisted of observation, detection, manual control and operation, with few demands to process tuning or fault management.

- Supervisory Control was the next stage. Technological developments increased the complexity of the machines and consequently the demands on the operator. When the demands to precision, speed, and sustained attention exceeded human capacity, manual control tasks were taken over by automation. Rather than being a part of the machine or the process, the operators gradually became supervisors that were supposed to step in when things went wrong. The tasks were generally part of the supervision and adjustment of a control system consisting of state recognition, fault finding, and scheduling of tasks during start-up and shutdown sequences and process tuning. 
- Cognitive Control is the present stage where humans and machines have increasingly come to be seen as a whole, a joint human-machine system, even though this is far from being achieved in every system design. More extensive automation has removed the operator even further from the actual process. Work is now mediated by information technology and allocated between humans and machines according to the nature of the process (and its physical implementation) rather than considerations of joint human-machine system functioning. It has now become necessary to provide a rigid process design for the human-machine system. A typical design based on a "top-down" hierarchy of analysis exposes the importance of the operator's performance envelope. In most process design cases however, efforts are limited to avoid exceeding the performance envelope under normal operating conditions, rather than preventing human error under upset or emergency conditions.

As described in the manual control scenario, the operator's task in many instances was to visit the equipment and gain a "Real Time" perspective regarding the performance of the ongoing processes. This interaction had an added advantage in that it provided a level of assurance from a production standpoint that critical processes, for instance, were operating within specified guidelines. Also from this perspective, safety aspects of the processes were included in the observational reports.

These safety aspects consisted of a combination of process knowledge and knowledge of equipment limitations including the functions of "over temperature" devices, pressure relieving devices, speed sensors/governors, flow indicators, and high or low level alarms. Operational procedures dictated that the operators have the ability to read and evaluate an 
analog display at the location of the equipment. In some instances, several outputs were required to be read for a considered course of action. The interpretation of the outputs and resulting proper response was directly contingent on the ability of the human operator to process the information and react. The correct interpretation of the data was the only safety barrier between the observed process and the welfare of employees in the immediate area. Therefore training and constant monitoring of the process was essential. These same types of decision events could have been applied to driving an automobile, flying an airplane, or operating any piece of machinery that required the interpretation of a set of data followed by a proper response or action.

\section{$\underline{\text { Modern Processes Development }}$}

The need for accurate measures of dynamic conditions and processes became apparent as economies began to emerge early in the Industrial Revolution. These measures included temperature, length, pressure, flow, speed, and a refinement of time. The standardization of units of measures continued up through the mid 1950's and 1960's. Acceptance of these standardized units began to accelerate as competitive world markets emerged.

The increased demand for a better quality and larger volumes of products throughout the $20^{\text {th }}$ century brought about a need for improved human-interface systems. In the chemical industry in particular, it was discovered that the ability to replicate certain chemical compounds and materials to exacting specifications guaranteed a profit base and allowed the producer of the products to acquire patents for those processes.

As design requirements for the processes and equipment were better understood, more advanced engineering methods emerged and were employed to assure that effective control 
designs and efficiencies were maximized. To maintain system safety, chemical processes relied heavily on the integrity of the mechanical equipment used in the processes along with operators, the human-interface system, to accurately monitor, assimilate, synthesize, and interpret system data for proper response or action if required.

Designers soon found that processes could have been further refined and modified, using existing equipment, by incorporating advanced technologies that eliminated some of the human interface capabilities. With increasing frequency the operator's role from a "hands-on perspective" in the chemical process began to diminish when control schemes were updated and retrofitted and the system became more sophisticated. Increased levels of sophistication often required that the focus on the human-interface function be concentrated in the areas of process safety and operator training in order to reduce the potential for human error.

Within the last 20 years industrial process information tracking and data gathering systems continued to change dramatically. Companies such as OSI/Witco, I.E. DuPont, and G.E. Plastics introduced a "Central Control" technology to augment Distributive Control System (DCS) designs in their respective chemical plant processes. These systems were analogous in that they provided a central location for all process data to be recorded, analyzed, synthesized, and responded to when necessary. Instrumentation manufactures such as Bailey Controls, Allen Bradley, Omega, Westinghouse, and GE, continually provided the chemical industry with new and improved process monitoring devices.

Advantages of the DCS system included the remoteness of the control process from the process equipment with one central location for related processes. Proponents of this type of system also suggested that there was greater safety for the operators should there be an upset condition, direct data comparison from several related processes. The convenience of 
fewer process operators within an otherwise congested area (less distractions) also enhanced the system design (Pedersen, Lind, 1999). However, the physical remoteness from the actual process equipment offered a distinct disadvantage in that the remoteness results in the inability to respond, as illustrated in the manual control scenario, to situations that required the presence of an operator in the immediate area. Other disadvantages included the reliance on data "communicated" to the control center by lines, cables, and radio frequencies and the idiosyncrasies associated with each method of communication.

Improved information tracking and data gathering systems became more reliant on digital signal input and digital data output rather than the analog devices that performed similar functions. These devices gained popularity due to the ease of input or output generation and data transmission as opposed to the physical "link" required by analog instrumentation. Digital systems also had the ability to present operators and engineers with more detailed display information for control responses.

The impact of the potential for human error was not originally a major focus or consideration in the design phases of the transition to digital equipment display and layout. More particularly initial system training did not regard "situation awareness" as an important consideration in the design of safety and process training scenarios (Tullis, 1980).

One major chemical manufacturer in the upper Mid-Ohio Valley implemented a "Hard Wire" system in combination with Radio Frequency Transmission (RF) that allowed, part of or all, data to be transmitted to and from control rooms and process equipment via digital signals and fiber optic cables. The operator's function was to merely observe the process and intervene if an undesired condition presented itself. This was very similar to the cognitive control scenario. 
To further enhance control systems a "Statistical Process Control" (SPC) system (Wheeler, Chambers, 1992) was introduced to provide a statistically acceptable operational range for the process and provide a level of situational awareness. This type of system would include control processes such as the "6-Sigma" design. The 6-Sigma design permitted the system designers to set a predetermined "operational range" for the process based on previous data and equipment capability. The desired operational range always fell within one standard deviation of optimum conditions based on data collected from similar processes or direct observations of the targeted process. Excursions from one standard deviation were allowed, provided that the frequency and magnitude was within preset tolerances. For example, if during the process observation it was noted that there were seven excursions either above or below the one standard deviation of optimum operational limits, the process would be designated as an "out of control" process. This condition may or may not have been a cause for action other than resetting the equipment or determining the source of the problem. Using an empirical statistical model, $68 \%$ (plus or minus one standard deviation) of all data would have been within the operational limits, $95 \%$ of all data would be within plus or minus two standard deviations, and if the process was shut down for emergency reasons while still recording data or experienced a "runaway" reaction it would have been considered within plus or minus three standard deviations. The latter condition would have typically caused alarms to sound and emergency procedures to be enacted. Three standard deviations above or below the optimum process base line gave the control scheme its generic name, "6-Sigma Process". SPC systems have been developed primarily to replace or augment the "decision making" process for larger complicated systems and critical process manufacturing. The SPC system incorporates "Software" which, along with added hardware devices, provides a level 
of flexibility to adapt to existing measuring and data transmission schemes (Wheeler,

Chambers, 1992). Coupled with a central DCS, operators had the potential to synthesize more information at faster rates. The SPC system also provided trending data in the process dynamic which in turn augmented a level of situational awareness.

Consolidated Aluminum's "Bens Run Recycling Plant" at Bens Run, West Virginia discovered that operator's were not capable of making consistently accurate decisions with equipment that had more that 10 data (input/output) points. A process furnace at this plant, designed with 23 separate data points, was modified in 1991 to combine the functions of a SPC package and a GE/Fanuc Series 6 Programmable Logic Controller (PLC). This modification allowed the "critical" decision making processes to be less traumatic for the operators in an "upset" process condition (Rasmussen, 1986).

\section{Operator Training}

The combination of these systems in various facilities had provided many opportunities for industry to refine processes and have better control of operations (Mullet, Sano, 1994). Companies, however, have not been completely successful in the "operator transitioning / training" to the new processes and control systems. This lack of success had been due, in part, to the focus on the design stage of the new processes. Comprehensive training in the new processes with emphasis on cognitive skills has not been a major consideration as the equipment and programs have been introduced to the process control environment.

The need for a higher level of skill training for the operators also was not consistently recognized as a priority when these systems were originally put in place. This trend 
continued, but as natural and cyclical attrition along with retirements in the workforce took place, specific training designed for existing control systems was more frequently implemented for new employees/operators. Designers and administrators originally visualized these automated control systems as enhancements that were " much easier to operate". Full consideration was not given to the impact of "Human Factors" in safety, training deficiencies, response degradations, and other cognitive constraints on the operator.

\section{$\underline{\text { Current Statistics }}$}

The Chemical Safety and Hazard Investigation Board (CSB) released the following general statistics on commercial chemical incidents for a 10-year period beginning in 1987. The report was a comprehensive collection and consolidation of data from 5 major federal reporting agencies and covered all areas except marine oil spills. The report contained 10.1 million incident reports and the principal findings were:

- $\quad$ Chemical incidents were recorded in $95 \%$ of the nearly 3,300 counties within the United States.

- $\quad$ Of 605,000 unique incidents, $42 \%$ occurred at fixed locations (chemical plants) and $43 \%$ were transportation related.

- $\quad$ About $1.6 \%$ of the incidents resulted in death or injury; $0.7 \%$ resulted in evacuations of workers or public; $27.1 \%$ resulted in property damage.

- $\quad$ Over the 10-year period, there were 2,565 deaths and 22,949 injuries reported. 
- $\quad$ All states experienced chemical incidents, but seven states accounted for nearly one half of the total - California, Texas, Ohio, New York, Illinois, Michigan, and Louisiana.

- Incidents were most frequently reported for chemical manufacturing and fuel companies.

- $\quad$ Gasoline was the chemical most often involved and there were 45 other chemicals involved with 1,000 or more incidents.

- Mechanical failures were cited as leading to $40 \%$ of the incidents and human factors were cited in $27 \%$ of the reports. Natural phenomena accounted for an additional $1 \%$ and the remainder, $32 \%$ were attributed to unknown initiating events (National Safety Council Injury Facts, 1999).

When asked for assistance in data gathering techniques, specifically "Does data exist that might provide a more focused review of the published National Safety Council facts regarding display effects on human error and incident rates," Mr. Phil Cogan stated "I doubt very much that this data exists (P. Cogan, personal communication, August 30, 2001). For one thing, there is no reliable data either on the total number of incidents, and, even less on "near misses". Data on digital displays and their effects is even less likely to exist".

\section{Problem Statement}

The problem of this research was to determine what impact the transition from analog to digital process display gauges had on human error and safety in the chemical industry. 


\section{Purpose of the Research}

The purposes of this research were to provide:

1. Focused quantitative safety data for process engineers, instrumentation manufacturers, and safety managers.

2. A determination of contributing factors for instrumentation display misinterpretation and response degradation as related to human error in chemical process operator functions.

3. Assistance in data identification that will facilitate training program development for safety professionals in correcting operator "response degradation".

4. Areas of training focus designed to enhance "situational awareness" for the interpretation of digital display outputs.

\section{$\underline{\text { Research Hypotheses }}$}

It was hypothesized that the transition from analog to digital display gauges in the chemical industry had no impact on the safety incidence rate at a .05 significance level.

\section{$\underline{\text { Assumptions }}$}

The following assumptions were made in this research:

Digital displays continued to displace analog displays in industry.

Data reporting agencies accurately monitored the chemical manufacturing industry. The order of the data collection and research did not affect the outcomes. 


\section{$\underline{\text { Limitations }}$}

The limitations of this research were:

1. This research was limited to data made available by the selected reporting entities.

2. Data reporting entities for publication and information dissemination were in compliance with all legislative, professional association, and industry standard practices guidelines.

3. Data collection was limited to the actual years investigated.

4. Databases used in collecting incident statistics were not all inclusive.

5. Data collected from individual chemical companies was proprietary.

\section{$\underline{\text { Procedure }}$}

The following steps were included in the data gathering and data analysis process for this research:

- Solicited and received permission from selected individual chemical manufacturers to review incident and training records prior to the conversion and after the conversion to digital gauges.

- Conducted literature research of prior studies and literature specific to instrumentation displays, industrial process training, process emergency procedures, process safety management, human factors, and control room design.

- Conducted research of incident statistics and specific industry events whose impact on the safety of all personnel was directly affected by the ability to properly respond to control display indications. 
Databases \& Internet Sites used for background data reference included:

United States Chemical Safety and Hazard Investigation Board National Safety Council (NSC)

Human Factors and Ergonomics Society (HFES)

- Conducted literature search in the fields of human factors, human error in manufacturing domains, chemical plant safety records, chemical plant safety history, chemical plant operator safety training. The literature review provided anecdotal reference to historical chemical plant incident events, identified causes and effects of display misinterpretation, and human error in the chemical industry as it related specifically to digital display misinterpretation.

Literature search included:

Peer reviewed journal articles

Professional periodicals relating to specific major events Accident summaries

Individual chemical companies

- Analyzed and synthesized collected data germane to the research topic in order to determine incidence frequency with relationship to human error and misinterpretation of display information.

- Statistical analysis was conducted using an ANOVA on the gathered incidence frequency data to determine if a statistically significant relationship at the .05 level existed between misinterpretation of display information and display format.

- An incidence frequency was established for events to determine if a significant relationship existed between the total number of human error events causing injury, 
death, or chemical release and the number of human error events due to display misinterpretation (analog) causing injury, death, or chemical releases.

- An incidence frequency was established for events to determine if a significant relationship existed between the total number of human error events causing injury, death, or chemical release and the number of human error events due to display misinterpretation (digital) causing injury, death, or chemical releases.

- Recommendations for training and further research were stated.

\section{Definition of Terms}

The following terms and definitions were used in this research:

Analog Display. A system of visual measurement display in which continuously varying values are represented by hands, dials, and sounds to indicate numerical amounts.

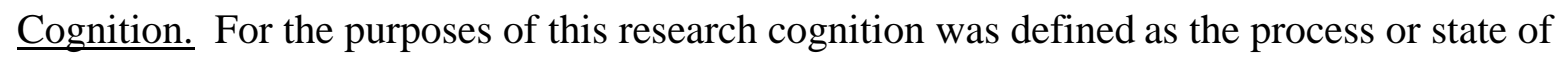
possessing, knowing, or recognizing, either visually or audibly, perception and judgmental abilities. The ability to visually process information in order to judge.

Digital Display. Digital displays are indicators of visual measurement in which continuously varying values are represented and displayed as numerical symbols to indicate numerical amounts.

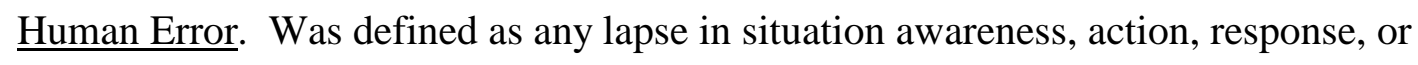
interpretation as a result of a data display output or indication that was incorrect whether or not it resulted in an incident causing injury, product or property damage, or unwanted release of a material. 
Hysteresis Effect. The "Lag" time between the event indicated in the display and the initiation of a proper response to the indication.

Incidence / Incidence Rate The Incidence and Incidence Rate were used interchangeably and defined for purposes of this research as those incidents or relevant events that had been factored as a proportional ratio to the man-hours worked at the researched facilities. The Incidence Rate was based on the Occupational Safety and Health Administrations' formula. Incident / Event. For purposes of this research the term incident or event referred to any abnormal or upset event that was involved with a chemical manufacturing process that caused or had the potential to cause injury, illness, death, or property damage to manufacturing personnel, neighboring population, or the environment.

PSIG. Was defined as Pounds per Square Inch Gauge.

Response. Was defined in this research as the action or lack of action as a result of a cognitive process.

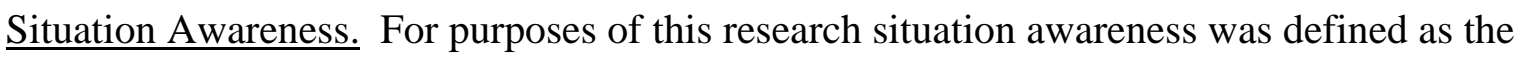
ability of a chemical plant operator to maintain a point of reference with regard to the safety of the process and all associated personnel while interpreting and correctly responding to multiple data displays relative to the process.

Transformational Loads. The additional activities that required a synthesis of indicated output information in order to properly respond to a monitored task. 


\section{Chapter II}

\section{Review of Literature}

\section{$\underline{\text { Introduction }}$}

This chapter contains descriptions and references to instrumentation display research, safety considerations, and emergency procedures, as well as human factor design considerations in chemical plant control room design. The continuing evolution of the Occupational Safety and Health Administration's Process Safety Management (PSM) regulations provided a background for illustrating the need for continued promulgation of new regulations specific to the chemical industry. The chapter also includes an outline of the origination, mission, and responsibilities of the Chemical Safety and Hazard Investigative Board (CSB). Specific issues relating to reporting regulations/structures and existing quantitative incident measures were addressed and discussed in order to provide a foundational relevance for agencies in place. Finally, this chapter contains documentation outlining the impact display gauges have had on human error incidents in the chemical industry.

\section{$\underline{\text { Influence and Developments of Industrial Process Displays }}$}

Initial human factors research, with respect to instrumentation displays, focused on determining whether or not differences did in fact exist between the responses to analog displays versus digital displays for chemical plant operators. Extensive research in this area with regard to military aviation, civil aviation, nuclear power plants, marine transportation, and civilian ground transportation suggested that analog instrumentation displays enabled operators to provide a consistent desired pattern of performance (Hanson, Payne, Shively, 
Kantowitz, 1981). Literature and incident reporting data did not reveal specific "chemical plant" operations or control room design investigations of past incidents. Relationships between the types of displays and resulting differences observed, i.e. process reaction times, display style/type, or training with regard to overall process safety and chemical plant operator training was not as abundant as aviation and military investigations. Similarities in the literature did, however, provide a basis for this research.

Manufacturers of instruments, controls, and display gauges inundated the industrial market with what they noted as "Best Available Technology". Many of these manufacturers and companies provided extensive training for generic operations and problem solving throughout the evolution of their respective product lines and had not historically taken into consideration variables in human capabilities and process performance (Roth, Bennett, Woods, 1987).

A paper presented in the Proceedings of the Human Factors Society $25^{\text {th }}$ Annual Meeting in 1981 by Hanson, Payne, Shively, and Kantowitz suggested that, overall, analog display formats were "far superior" to digital display formats within the confines of their experiments. The stated purpose of this research was to establish what performance differences, if any, existed between the basic display formats and to evaluate factors leading to these differences.

The results of two separate but related experiments by Hanson, et al, (1981), suggested that performance differences could be attributed to the operator's capacity in handling "transformational loads" imposed by the display format with reference to analog versus digital displays. 
Hanson, et al. further noted that the results of these and other experiments indicated preference of analog displays over digital displays from a design standpoint (See Figure A.01, Appendix A). In both experiments it was observed that digital displays had a longer detection time and were more sensitive to the number of displays that were monitored. Determining the effects of increased detection times and resulting confusion (human error) in process operations was not quantified in the noted experiments.

\section{$\underline{\text { Regulatory Agencies }}$}

Occupational Safety and Health Administration

The Occupational Safety and Health Act (OSHA) of 1970 was passed by Congress in order to reduce or eliminate hazards in the American workplace. The mission of the act was to "Assure so far as possible every working man and woman in the Nation safe and healthful working conditions" (29 CFR 1910, 1970). The act further provided for continuous standards development, enforcement, and compliance assistance for the employer in order to maintain a safe and healthful workplace. In February, 1992, OSHA published their final rule in the Federal Register (29 CFR 1910.119) of developed standards on Process Safety Management (PSM) of Highly Hazardous Chemicals (Federal Register, 1992). Standard 1910.119 provided specific safety guidelines for manufacturing processes, storing, transportation, and human exposure for a published list of highly hazardous chemicals. Chemical producers and users were given 5 years to bring there processes and documentation up to PSM standards and to set in place routine procedures for developing new designs, and engineered process documentation as well as documented safety measures for the hazardous substances. 
The PSM Standard provided "pro-active" sequences for making process changes, implementing new processes, and outlined procedures for safety scenarios to be implemented in those designs. Tools for these sequences included but were not limited to "Fault Tree Analysis", "What If" scenarios, "Total Quality Management", and a variety of other mechanisms designed to review all possible events surrounding processes involving highly hazardous chemicals (Federal Register, 1992).

\section{United States Environmental Protection Agency}

The Clean Air Act Amendments of 1990 created the United States Chemical Safety and Hazard Investigative Board (CSB) as an independent, scientific investigatory agency with no regulatory or enforcement powers. The CSB structure was closely modeled after the National Transportation Safety Board (NTSB), which routinely investigated transportation accidents both in the industrial and civilian situations.

The mission of CSB board was to "Investigate accidents in order to determine the conditions and circumstances which lead up to the event and to identify the cause or causes so that similar events might be prevented" (CSB, 2000).

As the board was created, it was designed to operate and function independently of the Environmental Protection Agency (EPA) and the Occupational Safety and Health Administration (OSHA) but was required to collaborate with these and other agencies as events required. With CSB as a noted exception, a majority of the 1990 Clean Air Act Amendment articles and regulations were placed under the control of the EPA. During the time that the CSB was created in 1990 it was not officially funded nor did it begin operations until January 1998. Congress recognized that the board should have the unique ability to 
identify serious chemical hazards not otherwise addressed by the Department of Labor's OSHA or the EPA.

The CSB worked through multi-faceted, collaborative partnerships with stakeholders, which included chemical companies, trade and professionals associations, insurance companies, and local/federal/state environmental agencies. The CSB also acted in concert with EPA and OSHA in data gathering and investigation reports to minimize duplication of reports. The CSB developed a Memoranda of Understandings (MOUs) with OSHA and the EPA as well as the NTSB. Finalization of a MOU with the Agency for Toxic Substances and Disease Registry augmented the CSB's ability to consult on human health impact issues (Poje, Rosenthal, Taylor, 2001).

The CSB used many of the tools of the OSHA PSM standard to facilitate investigations of process failures and accidents. Material Safety Data Sheets (MSDS), for example, were a data tool that provided several federal agencies with basic non-proprietary chemical substance information for review by company employees, material transportation agencies, and first response agencies. All EPA first responder agencies were trained to use MSDS sheets as well as other mandated emergency procedures that involved highly hazardous chemicals.

Prior to the establishment of these agencies and the PSM Standard, there were 14 different agencies engaged in accident/incident prevention-related activities with no central accident data collection or locus (Poje, Rosenthal, \&Taylor, 2000). 


\section{$\underline{\text { Data Collection }}$}

After the incident at Union Carbide's methyl isocyanate (MIC) plant in Bophal, India was closely followed by another release incident at Union Carbide's sister plant in Institute, West Virginia, public concern was very influential in promulgating a new law in section 112 (r) of the 1990 Clean Air Acts (CAA) Amendment. The thrust of this new rule was aimed at preventing and minimizing consequences related to accidental chemical releases. The rule encompassed both public and private facilities that manufacture, process, store, use, or otherwise handle regulated substances or those substances specifically noted in OSHA's 1910.119 PSM standard appendix “A”, and further established procedures for specific threshold quantities ranging from 500-2000 pounds (Kleindorfer, Feldman, \& Lowe, 2000).

The rule also required regulated facilities to prepare and execute Risk Management Programs (RMP) that provided hazard assessments, accidental release preventions, and emergency response programs. To date, 15,000 facility reports have been received by the EPA containing information regarding each facility's accident history, accident prevention program, and potential accident consequences.

The rule also specified that regulated facilities maintain a five-year history of accidental releases and submit this history to the EPA (Belke, 2000). The release of this information to the general public has been restricted to the agencies involved in data analysis and to "qualified researchers". Local Emergency Planning Committees (LEPCs) were provided data and information necessary for emergency planning on an as needed basis by the local chemical facilities.

OSHA required injury and illness reporting on two separate forms. The OSHA No. 200, (now 300 Log) Log and Summary of Occupational Injuries and Illnesses and the OSHA 
No. 101 (now 301 Log) Supplementary Record Of Occupational Injuries and Illnesses both provided information regarding illnesses and injuries sustained while the employee was at the job site. Regulation 29 CFR 1904 mandated under what conditions incidents qualified to be recorded in the No. 200 Log. All incidents recorded in the No. 200 Log must have a completed No. 101 record to match them (OSHA, 2001). The old No. 200 log and the old No. 101 record were not investigative type recordkeeping tools, but contained enough information to provide a basis for further investigation.

The CSB's original role was to gather data collected from other agencies and entities for the purpose of establishing baseline metrics for the general chemical industry. To this end, the CSB compiled data from five existing federal data bases, and identified reported chemical incidents that occurred within the United States over a ten-year period starting in 1987 and ended in 1996 in order to identify trends. This process is currently ongoing and the intended outcome was to develop stakeholder's consensus on key metrics, and to develop and implement a publicly accessible system that could be used for prevention measures (United States Chemical Safety and Hazard Investigation Board, 2002).

Additional sources of data were collected for industrial facilities involved in this project. Safety audits and inspection of chemical processes from a maintenance and operation perspective aided in developing event lines regarding the transformation from analog to digital displays. Periodic safety and training reports facilitated the identification of areas of data concentration. Incident reports at participating facilities provided direct evidence of incident occurrences related to display types with regard to established event lines. These incident reports were analyzed for content appropriateness relevant to the specific focus of the research. 


\section{Decision Making Processes and Safety}

\section{$\underline{\text { Prior Research }}$}

The concern for training in decision-making processes attracted considerable interest in the last half of the $20^{\text {th }}$ Century, mainly due to a number of spectacular incidents in complex industrial systems. The more famous of these included the explosion at the Flixborough plant (1974); the airplane collision at Tenerife (1977); the accident at the nuclear power plant at Three Mile Island (1979); the explosion of the Challenger space shuttle (1986); the meltdown at the nuclear power plant in Chernobyl (1986); and the multitude of problems on the space station MIR (1998). The Bhopal Incident in Bhopal, India stood alone as the hallmark to which the chemical industry regarded the beginning of the "New Era" of safety consciousness in chemical processes.

In the above-mentioned incidents, failures of human action and judgment had often been cited as a contributive cause. In an increasing number of chemical accidents the main cause or "Root Cause" was attributed specifically to "human error". The estimated number had grown from $30 \%$ in the 1960 's to as high as 70 to $90 \%$ at present (Hollnagel, E., 2001).

Hollnagel noted that there were a number of reasons for this trend, which included: Technological systems have become more complex, hence more difficult to control; Improved models/methods for "human error" analyses have made this cause more likely; Technological systems have become more reliable, hence raising the relative number of other causes; or "It is sometimes cheaper and more convenient to put the blame on a human than to redesign an entire system" (Hollnagel, E., 2001).

Wickens $(1980,1984)$ proposed a "Multiple Resource Theory" (MRT) which provided an investigative basis for determining the effects of display formatting on dynamic processes. 
This theory predicted that simultaneous tasks, which rely on the same data or display stimuli, might show performance decrements as task difficulties increase.

Boles and Wickens further collaborated on the MRT design to assess decision task performance changes in "dual-task" scenarios. The MRT was tested to predict issues concerning display formatting. Expectations, with reference to the refined MRT, were that superior performances should be obtained with a mixed display format. Results also suggested a support of previous findings and indicated that the integration/non integration task distinction was not an important variable to take into account when designing process displays (Payne \& Lang, 1995). Two factors accounted for this conclusion; 1. Tasks can be practiced to a suitable degree of proficiency, and 2. Some tasks are difficult to characterize as integration or non-integration. In addition, Payne and Lang noted that other than the proximity compatibility principal (Barrett \& Wickens, 1988; Carswell \& Wickens, 1987) there were few references to integration and non-integration tasks with respect to integrated display and integrated controls.

Payne and Lang provided an approach to determine relative advantages and disadvantages of "mixed" and "pure" display formats with reference to integration and nonintegration tasks. They defined mixed displays as concurrent analog and digital display format presentations (Figure A.01, Appendix A). Pure display formats were either digital or analog exclusively. Through the course of 4 experiments it was concluded that analog displays provided shorter response latencies (Payne \& Lang, 1995). It was found that it did not take participants as long to respond to instrumentation presented in an analog format.

Additional research, however, demonstrated that analog superiority had been obtained using a number of different and varied tasks such as discrete trials and continuous process 
monitoring with participants from various backgrounds including college students, and novice and experienced airline pilots (Hanson, Payne, Shively, and Kantowitz, 1981).

Boles and Wickens (1987) noted that their study revealed large differences in the overall speed of responses. The noted differences were specific to analog versus digital or verbal (audio) displays in combination with the integration and non-integration tasks. Response latency was the primary performance measure in those studies.

With reference to the response latencies, P.S.E. Farrell (1999) provided a study that explored three perspectives in psychological phenomena processes and defined them as: (1) the ideal transmission; (2) accuracy trade-off and interference effects; and (3) the sampling strategy phase. It was anticipated that these combined phenomena would provide a potential explanation for the "Hysteresis Effect" (Response Lag) in information processing and response. Response lag or the inability to make timely decisions and to respond properly to real time situations became a major safety concern within the process design scenario.

Farrell concluded that short-term memory and the expectancy hypothesis do not combine to fully explain the hysteresis effect in information processing. Notably the variation in processing time for each individual rather than the amount of information processed and responded to, suggested a more likely explanation for the hysteresis effect. Reaction time to stimulus may vary with process demand and is manifested in a speed-accuracy trade off mechanism (Kantowitz \& Sorkin, 1983; Pew, 1969). It was also noted that reaction time varied with spatial proximity of the information/data source (gauges, dials, enunciators) (Wickens, 1992). Wickens also suggested that the "time domain" might also be compromised when two similar items (instruments or data stimuli) interfere with each other when sharing a close temporal proximity, thus causing the reaction time to increase. This interference could 
be observed as either proactive or retroactive interference (Farrell, 1999). The focus of Farrell's research was the human capabilities of air traffic controllers to process information in a timely fashion.

Kantowitz (1981) theoretically reasoned that imposed additional transformational loads caused the digital display inferiority in the operator responses. This hypothesized transformational load in turn was thought to consume any spare operator processing capacity for unexpected alarm conditions. Tullis (1980) suggested that differences similar to the ones described in the previously noted experiments could be overcome by providing more frequent training on digital displays.

Discussions and literature reviews noted with respect to this experiment included the associated topic areas of "Attentional Processes", "Accidents, Safety, Human Error", and "Displays and Controls". These listed topic areas along with references to previous research were examined with respect to the stated research questions and provided a basis for further study.

\section{Training Approaches}

Previous Human Factors Research

Rasmussen (1986) suggested that the internal anatomy combined with the processes of the system being observed provided an interrelationship that does not exist when examining or observing data or behaviors individually. The design of problem solving training for optimum "Conscious Data Processing" must be based on a model that can be represented as either internal or external for use in data processing. Rasmussen defined internal as "mental" and external as visual objects such as drawings, dials, gauges, and or diagrams. 
The internal/external properties of a system process and the data representation together provided a basis for the transformational load. System designers and engineers tend to consider a "visual aid" form of process system depiction as optimal for predictable and desired behavior rather than the internal model that would have naturally developed over time with repeated operator use (Rasmussen, 1986).

Interacting successfully with a physical process system required that the state of the system be known and understood. Included within this system state were the actions that had to be identified for proper response and behavior for predicted future behavior (Rasmussen, Pejtersen, and Goodstein, 1994). It was suggested that good design foundations for internal process system models should be based on the proper training design relevant to the subject process system.

\section{$\underline{\text { Industrial Training }}$}

Murnaw, Roth, Vicente, and Burns (2000) noted that operator's "on the job" experiences, abilities, and strategies for acquiring systems knowledge in general, augments formal training to the point where there appears a seamless familiarity in observed behavior. They further suggested that the training programs for nuclear power plants, for instance, were more matters of regulation required certification rather than "on going" skills enrichment. Another noted obstacle was that, in industry, since time was usually at a premium, "on the job training" was the preferred management strategy for training most operators.

Training approaches differed in thoroughness and content throughout plant and the industrial complexes. Rasmussen, Pejtersen, and Goodstine, (1994) suggested approaches to training which would provide a perception of "Boundary Characteristics". Boundary 
characteristics established for specific training sessions and which were specific to instrumentation displays would provide an implied spatial-temporal perception of the involved process and its limits. With boundaries established and then communicated prior to training exercises, participants were given opportunities for learning system characteristics and more importantly process recovery techniques for emergency scenarios (Rasmussen, Pejtersen, and Goodstine, 1994).

Process indicators (dials, gauges, charts, displays) in all instances provided an attempt to communicate boundaries of the involved monitored process. It was hypothesized that a formal familiarization process would enhance sensitivity to these boundaries through spatialtemporal perception/cognition and subsequent required sensorimotor control. In order for this familiarization process to be successful, Rasmussen, et al, (1994) stated that the design strategy must incorporate the creation of a truthful and ecologically correct work interface.

The correct work interface design for training was essential in removing obstacles that tended to be present in developing skills and knowledge of adult learners. Shea (1994) provided a listing of general factors that differentiated experienced adult learners from nonexperienced younger learners. Of major concern, and one of the factors noted by Shea, was a low tolerance of the adult learner for training exercises and experimentation that appeared to be remote from a usual task. This low tolerance coupled with other threatening factors such as stress, insecurity, and reluctance (for various other reasons) to try or participate in new processes provided challenges for designing training scenarios that addressed the task problem area. Additional attributes considered for experimental design and training were described by Shea as generational differences, cognitive styles, prior learning experiences, and demographical differences. 
Dick and Cary (1996) defined two groups within an instructional process. The larger group was the "Target Population" and within that group were the "Try-out Learners". The Target Population was defined as the "abstract representation" of the largest range of learners possible within the spectrum of the subject matter. The Try-out Learners were, on the other hand, a convenience sample from within the Target Population. It was noted that wide spectrums of skill and academic levels usually existed within the Target population. It was for this reason that the compatibility and adaptability of the experimental/training site must simulate, or at least be as familiar as a common workplace environment. With this realization, consideration was given to the fact that the Try-out Learners were exposed to scenarios that were, at best, global in nature and results weighted with the global variables in mind (Rasmussen, et al, 1994). The design then, of a particular research, should provide opportunities for all participants to be evaluated and more importantly, allow for all participants to be exposed to skill enhancing and instructional processes. During training and subsequent interventions processes a method of rigorous evaluation would have to be present (Kazdin, 1982) in order to simulate workplace-training environments. 


\title{
CHAPTER III
}

\author{
Methodology
}

\section{$\underline{\text { Statement of Problem }}$}

The problem of this research was to determine what impact the transition from analog to digital process display gauges had on human error and safety in the chemical industry.

\section{$\underline{\text { Research Hypotheses }}$}

Hypotheses. It was hypothesized that the transition from analog to digital display gauges in the chemical industry had no impact on the safety incidence rate at a .05 significance level.

\section{$\underline{\text { Population }}$}

The chemical manufacturing companies involved in this study had a combined chemical manufacturing experience of over 170 years. The plants were located in the MidOhio Valley and were considered to be representative of chemical manufacturing throughout the country. All of the selected plants began manufacturing various chemicals in the MidOhio Valley within a 14-year period between 1941 to 1955 . In all cases, the companies whose plants were selected were well established in other locations throughout the United States prior to placing facilities in this area.

Data gathered and examined, with written permission from each facility, included the OSHA 200 logs and OSHA 101 summaries as well as engineering documentation regarding installation of digital processes. Other documents reviewed were the facility's "incident reports". The incident report is not a document that was required to be completed by OSHA 
regulations but was regarded in industry as an essential document for finding "root causes" and preventing incident reoccurrences. The identification of the root cause and further investigation of incident reports was the narrower focus for determining which incidents were to be categorized as "human error" and related to misinterpretation of control room displays. The engineering records that were required to be up to date and available under OSHA Process Safety Management Guidelines served as a reference base. Additional data was collected from government agencies as needed. These agencies included the United States Environmental Protection Agency (EPA) and its satellite agencies, the United States Department of Labor and satellite reporting agencies, and the independent chemical manufacturers.

\section{Procedures}

Literature research and reviews of existing reported governmental data, selected chemical manufacturers safety records, and engineering data relating to the phasing in of digital process displays for those selected chemical manufacturers were conducted through the following means:

Databases:

Individual plant records Incident Investigations OSHA Recordables

OSHA Standard Industry Classification (SIC) Codes for Recordable Incidents United States Chemical Safety and Hazard Investigation Board Reports (CSB) 
Unites States Environmental Protection Agency (EPA) Chemical Emergency

Preparedness and Prevention Office (CEPPO)

National Institute Occupational Safety and Health (NIOSH)

Internet sites:

EPA

CSB

Center for Risk Management and Decision Processes

As presented in the previous chapters, the literature research revealed that $27 \%$ of the reported 605,000 incidents involving chemical manufacturing processes over a ten-year period were attributed to human error. These incidents involved lost workdays, injuries, and fatalities which were recorded and reported to OSHA and which were, in turn, included in the United States Department of Labor Occupational Illness and Injury database. All accidental releases of chemicals reported to the United States Environmental Protection Agency were included in the reporting database regardless of whether the releases resulted in an illness, injury, or defined as a near miss. The preliminary review indicated that these databases could be combined to provide a basis of comparison and study for individual chemical manufacturers.

The 2 selected chemical manufacturers granted permission to the researcher to examine safety records and manufacturing records. The records were examined with the assistance of either the plant safety manager or his designee. Proprietary agreements between the researcher and the selected chemical manufacturing plants were agreed to and signed in order to protect the integrity of the processes and the confidential nature of the data. 
Preliminary conversations with the prospective participants and brief reviews of engineering records provided evidence that the conversion to digital displays began in the early 1980's. This was followed by a transition period of about 6 years. Around the time period of 1986 to 1987 several process operating units within the prospective facilities had partially converted to the digital display format. During the next 7 years varying degrees of digital display integration took place in these process units. The next 7-8 year period revealed a transition back to analog-looking digital process controls. It was not possible to collect the data that would have indicated the incidents prior to and during these different phases because records prior to 1993 were eliminated. Each facility had a policy in place that allowed the records older that 8 or 9 years to be purged.

The data that was available was, however, of the type and quantity that would lend itself to analysis. Of the two facilities, Facilities Group "A" (Group A) exhibited a data range from 1995 to 2001 and Facilities Group "B" (Group B) exhibited a data range from 1993 to 2001. The total period of time reviewed and examined did not exceed 20 years.

It had originally been proposed that the research be a "Before/After" format with a designated transition period of time in which, supported by engineering records, a facility would have converted to digital displays. This would have provided a historical (before/after "linear") comparison between the two types of display formats. However in reviewing the data at the subject facilities, it also became apparent that analog displays remained in use and were relied upon as much as digital displays. Therefore the existing data presented and opportunity for a "concurrent event" research format for comparison.

The frequency with which the data appeared as either analog or digital display generated events provided an opportunity for analysis and comparison within the same facility 
at the same relative period of time. Further, the opportunity also presented itself to compare two facility's data for the same relative period of time under similar conditions. Each facility also exhibited detailed reports and records for all events examined. Using the above conditions also provided an opportunity to compare the facilities incidence rates to national incidence rates within similar Standard Industry Codes (SIC).

The incident/event data examined and included within this study were noted as instrumentation and display-related and was arranged in one of the following categories:

1. Misinterpretation of display (operator confused the read-out or transposed numbers indicated which resulted in an event)

2. Delayed response (operator noted the alarm of an indicated process change and did not respond in a timely resulting in an event)

3. Implied as human operator error without specific clarification (report indicated that there was a level of human error involved in causing the event which was related to but specifically noted as display related) 4. Misunderstanding of process operations (operator observed the indications correctly but did not respond appropriately resulting in an event)

Frequency rates for both governmental data bases and private industries records were illustrated by multiplying the number of qualifying incidents by 200,000 (100 employees working full time for 1 year) [On-line] (U.S. Department of Labor, 1997, p74) and dividing that result by the total number of man-hours worked during the period of time examined. The following is an example of the calculation:

Formula $1 \quad$ (Total qualifying Incidents) X 200,000 Total Man-hours worked for the period examined $=$ Incidence Rate 
Quantitative analysis of the criteria data provided a basis for determining whether an impact, at the .05 significance level, existed when comparing analog and digital incidence frequency rates to the total safety incidence rate in the chemical industry. The analysis also provided a basis for determining the relationship between chemical industry incident frequency rates and regulatory reporting data for the same period of time using the same defined criteria. Finally, data was analyzed to determine if the transition from analog display formats to digital display formats, at the .05 significance level, impacted the overall chemical industry incident rates for the years examined.

The results and conclusions drawn from this analysis defined the nature of the impacts that transitioning from analog to digital instrumentation display formats has had on the chemical industry.

\section{$\underline{\text { Analysis Format }}$}

In reviewing the data at the subject facilities, it became apparent that analog displays remained in use and were relied upon as much as digital displays. Therefore the existing data presented and opportunity for a "concurrent event" research format for comparison.

\section{Summary}

In summary, the number of participating facilities for the research was two. Neither facility maintained or stored event records back beyond 1993. Each facility exhibited concurrent analog and digital event data records. 
Demographically the two facilities maintained operations in the Mid-Ohio Valley and were located approximately 28 miles apart. One facility was in a rural setting; the other was in an urban setting with several other chemical plants in close proximity. There was a difference of approximately 200 people employed between the two facilities. Each facility drew employees from a different population base. 


\section{CHAPTER IV}

Analysis of Data

\section{$\underline{\text { Introduction }}$}

The data for this research was gathered during visits to each participant's plant site using a data collection form (Figure B.01, Appendix B). The records that were available at the visited sites were combined into "Event" records rather than individual "Safety Incidents" or "Environmental Incidents". At one facility the records were cataloged in the Health, Safety, and Environmental Department. In the other facility, the records were kept by the Safety Department. Therefore, the recorded events included both safety and environmental incidents, which may or may not have met conditions and requirements mandated by OSHA or the EPA for being recorded or reported to the respective governmental agencies.

\section{$\underline{\text { Analysis Structure }}$}

Determining the effects or impacts of converting from analog to digital display formats on the total incident occurrences offered several analysis options. The data in this chapter has been presented in the following manner to provide a progression indicating individual characteristics of the following:

- Combined Data for Group A and Group B (Table 1, page 44)

- Individual Group Data for Group A and Group B (Table 2 \& Table 3, pages 50 \& 53)

- Individual Group Incidence Data with Bureau of Labor Statistics Data as background information (Table $4 \&$ Table 5, pages $60 \& 62$ ) 
The record keeping arrangements examined were found to be similar for most chemical plant sites as Safety and/or Environmental issues have the potential for causing injuries and illnesses in both the local plant environment and surrounding areas. Data collected and exhibited for this research included all events on record at each facility.

\section{$\underline{\text { Analysis of Data }}$}

The research used two major indices (Analog or Digital related events) to examine the possible or potential differences between analog and digital display related incidents. Within these two indices, four "Cause Code" sub-indices or categories were developed as described in Chapter 3, page36. The sub-indices provided a focus on causes for the incidents being reviewed. These sub-indices were "Implied Human Error", "Misunderstood Process", "Misread the Display", and "Failure to Respond". The "Cause Code" data totals were listed in Table 1.

Table 1 provides the tabulated data for the combined groups. The Incidence Rates illustrated in the last two columns represent the analog, digital, and overall human error calculations using Formula 1 as described in Chapter 3.

Table 1 contains the 346 reviewed events characterized as "Human Error". Of these events, 64 were categorized as display related events and noted in the appropriate designated cause code category.

The last three columns in Table 1 illustrate the "Incidence Rate" for analog related incidents, digital display related incidents, and the total human error incidents for the combined facilities data. The incidence rate was defined as a function of the total events in 
each category multiplied by 100 man-years or 200,000 man-hours divided by the actual manhours for that particular year.

Table 1

Combined Group Data

\begin{tabular}{|c|c|c|c|c|c|c|c|c|c|c|c|}
\hline \multicolumn{12}{|c|}{ Combined Facilities Research Data } \\
\hline \multirow{3}{*}{ Year } & \multirow{2}{*}{\multicolumn{2}{|c|}{\begin{tabular}{|c|} 
Display \\
Related \\
Incidents \\
\end{tabular}}} & \multirow{3}{*}{ Man-hours } & \multirow{3}{*}{$\begin{array}{c}\text { Total } \\
\text { Human Error } \\
\text { Events } \\
\text { Recorded } \\
\end{array}$} & \multicolumn{4}{|c|}{ Cause Code } & \multicolumn{3}{|c|}{ Incidence } \\
\hline & & & & & \multirow[b]{2}{*}{ FR } & \multirow[b]{2}{*}{$\mathrm{IH}$} & \multirow[b]{2}{*}{ MP } & \multirow[b]{2}{*}{ MD } & \multicolumn{2}{|c|}{ Rate } & \multirow{2}{*}{\begin{tabular}{|c|} 
Rate \\
Human Error
\end{tabular}} \\
\hline & ANA & DIG & & & & & & & ANA & DIG & \\
\hline 1995 & 4 & 4 & $3,220,046$ & 48 & 2 & 1 & 3 & 2 & 0.248 & 0.248 & 2.981 \\
\hline 1996 & 6 & 6 & $3,033,435$ & 52 & 0 & 8 & 2 & 2 & 0.396 & 0.396 & 3.428 \\
\hline 1997 & 5 & 5 & $2,782,973$ & 59 & 1 & 6 & 3 & 0 & 0.359 & 0.359 & 4.240 \\
\hline 1998 & 3 & 7 & $2,604,627$ & 33 & 0 & 4 & 5 & 1 & 0.230 & 0.538 & 2.534 \\
\hline 1999 & 4 & 5 & $2,508,703$ & 54 & 3 & 2 & 2 & 2 & 0.319 & 0.399 & 4.305 \\
\hline 2000 & 1 & 6 & $2,314,418$ & 50 & 3 & 1 & 2 & 1 & 0.086 & 0.518 & 4.321 \\
\hline 2001 & 5 & 3 & $2,247,800$ & 50 & 1 & 4 & 1 & 2 & 0.445 & 0.267 & 4.449 \\
\hline TOTALS & 28 & 36 & $18,712,002$ & 346 & 10 & 26 & 18 & 10 & & & \\
\hline
\end{tabular}

Note: $\mathrm{ANA}=$ analog; Dig = Digital; FR = Failure to Respond; IH = Implied Human Error;

MP = Misunderstood the Process $;$ MD = Misread the Display

A total of 2,073 events were reviewed from all group facilities. A total of 1812 events were used for the purpose of testing the hypothesis. The remaining 261 events were counted in the totals, but since these events were exhibited for year periods, 1993 to 1994, in only one analysis group, they were not used in the final statistical analysis. This eliminated a potential bias in the data. The data represented in the 1812 events denoted the same span, 1995 to 2001, of seven years with all groups.

The original intent of the research, as described in the Chapter III Addendum, was to review and record applicable data and arrange it in a "Before/After" matrix for the purpose of 
illustrating analog events prior to a period of time over a span of years and then follow up with a matrix of digital display events for approximately the same span of years. As the data was gathered it became apparent that records of events available in the subject facilities did not exist back beyond the year 1993 .

During the data collection and analysis process it was determined that there were as many analog instrument displays in use as there were digital. Access to process instrumentation engineering records and major capital improvement project records indicated a two-fold trend. One trend illustrated that some new digital display equipment purchased for control rooms and process control centers functioned as analog instrument displays. The control logic and operation was digital, but the display looked like and functioned as an analog display. Some were very good representations of analog displays and some were more "cartoon like." A second trend noted was that a standardization process was being implemented with each newly engineered control display project. This standardization continued to allow engineers to "hide" non-critical process data from the operators view and provided a means for the data to be recorded and printed to a hard copy. The standardized displays provided a "Real Time" assessment of the critical processes in progress without all of the otherwise distracting background data being displayed concurrently during the process. Color codes were noted on displays where the entire analog-looking display would change color and provided an extra measure of recognition for the operators. This standardization of colors is designed to help operators in the decision making process during upset conditions.

In reviewing the event reports it became necessary to establish parameters for categorizing events. The structure of the existing event report form at the facilities accommodated this necessity by exhibiting a category for "Human Error." The event records 
were reviewed in their entirety twice to ensure that no human error events were overlooked. The human error events were isolated and reviewed again to assure that the event qualified for a display related incident. In most cases the report narrative described in great detail actions and circumstances that surrounded the events. From the year 1998 to present, the reports became more detailed as efforts at the facilities increased to determine the "root cause" of the incidents. These two report characteristics expedited gathering and categorizing the data that is used in the final analysis. Several reports in each of the groups required further investigation to clarify qualification status for the research. These tasks included questioning the operators, actual visual inspection of the unit in operation and a further review of engineering records.

Data and observations indicated that, in general, analog displays tended to be near or on the equipment being operated, and the digital displays tended to be more abundant in control rooms or on remote panels. However, there were exceptions to these observations.

Data illustrated in Figure 1 indicate an overall declining "man-hours worked" trend of $30 \%$ during the observed span of time. This occurs when there has been a reduction in force or premium time (over-time) has been reduced. Therefore, since the Analog and Digital Incidence Rates remained relatively the same (or within .4321 (Incidence Rate) points), incidents per capita increased. The Total Human Error Incidence Rate also indicated an overall trend increase, except for the year 1998, further supporting the proposal that there was an increase in the per capita human error type events within the specific research groups. 


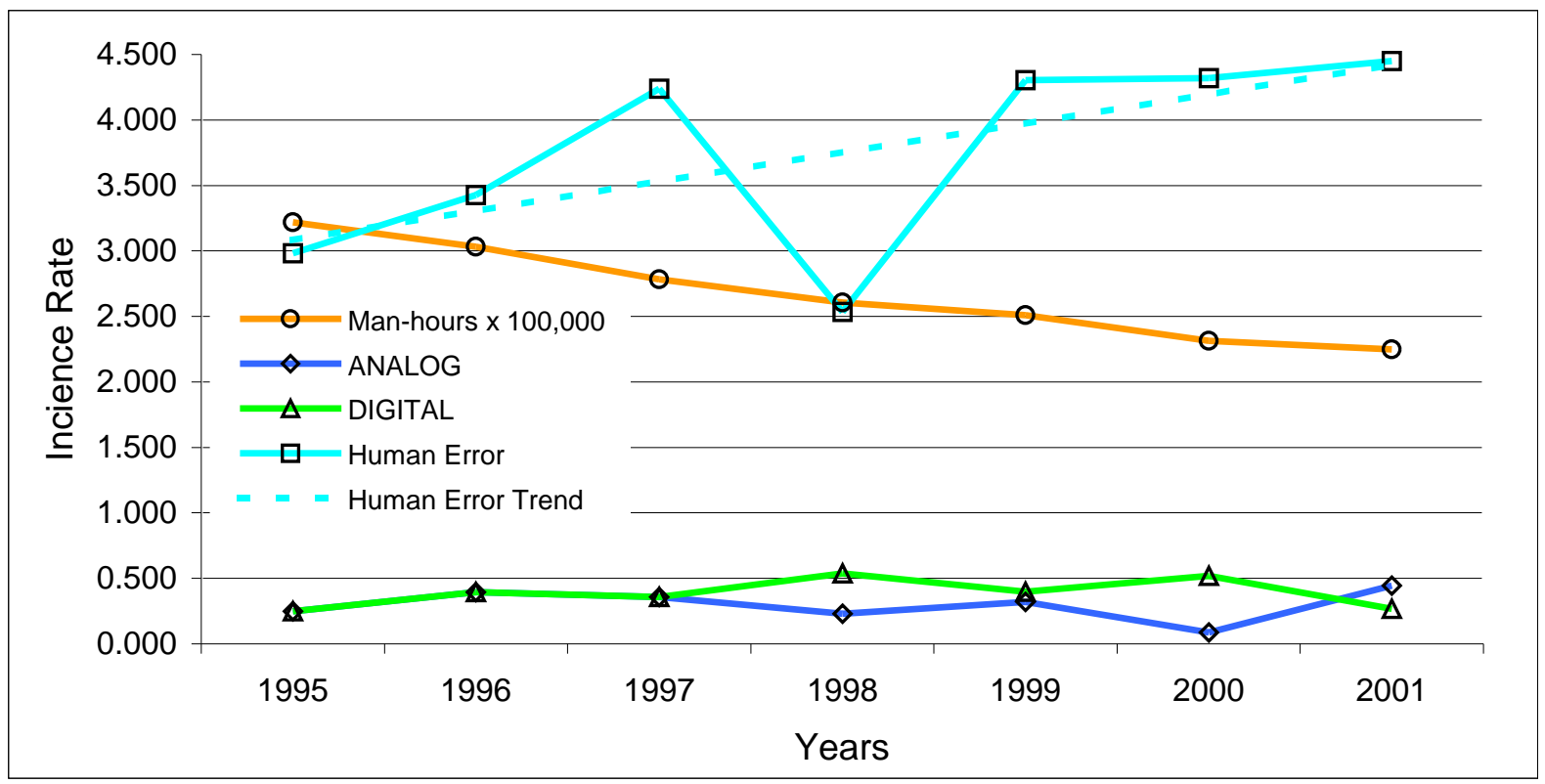

Note: The identified Analog /Digital Incidence Rates were the same in 1995, 1996, and 1997.

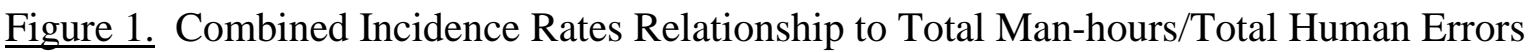

Figure 2 indicates the actual combined incidents and their associated trend relationships. Two of the four categories; "Implied Human Error (IH)" and "Misunderstood the Process (MP), trended downward during the research period. In the two remaining categories; "Failure to Respond (FR)" trended up and "Misread Display (MD)" remained level. The trend lines in Figure 2 indicated a condition that was not influenced by the number of man-hours worked during the period. Therefore, the cause codes represented indicated that, without considering any other influences on the data, there was an identifiable or focused area where there was an opportunity for intervention. 


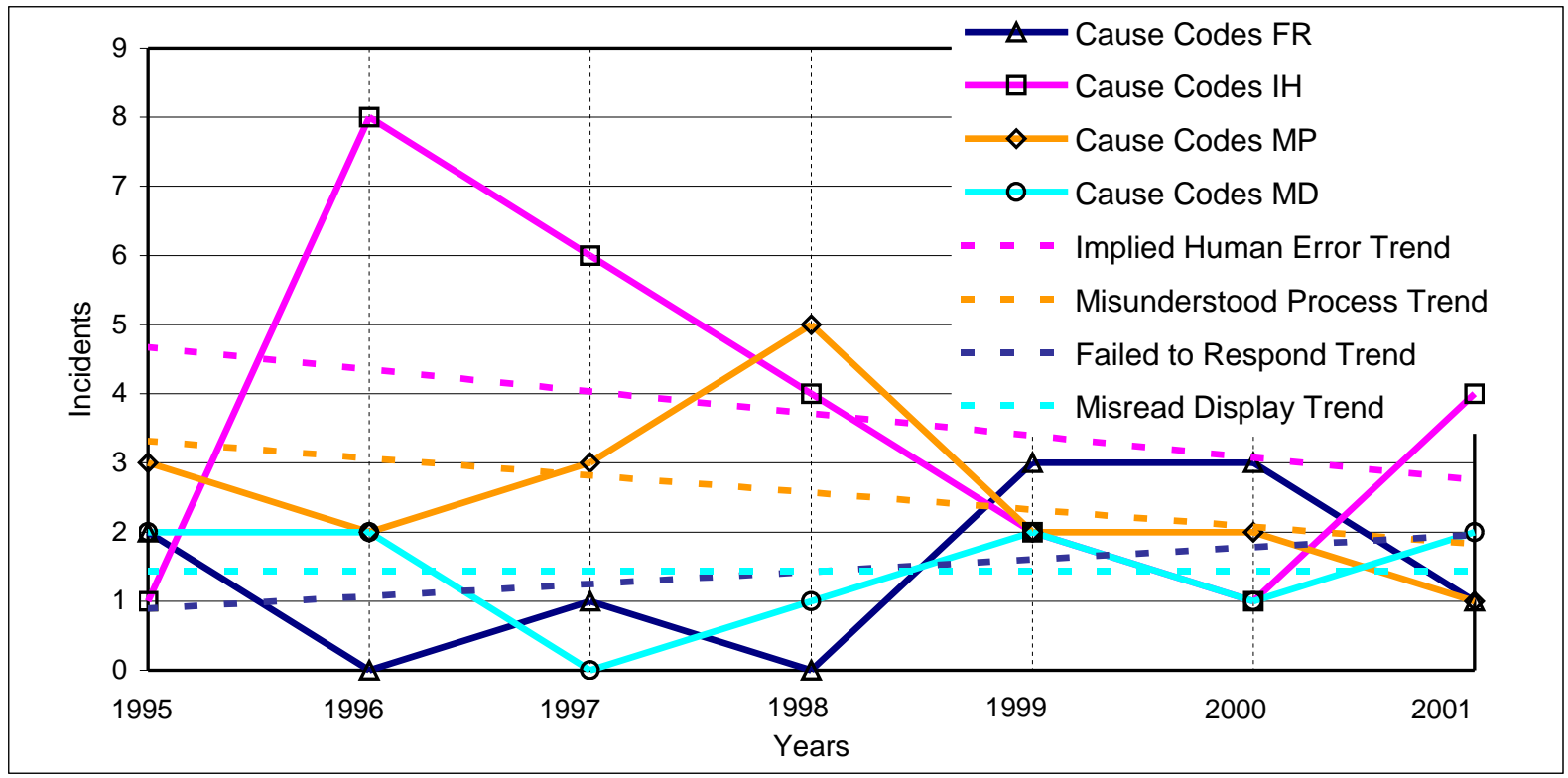

Note: Trend lines for each data group are illustrated as dashed. FR =Failure to Respond; $\mathrm{IH}=$ Implied Human Error; MP = Misunderstood the Process; MD = Misread Display.

Figure 2. Combined Incidents by Cause Codes

Figure 3 displays the combined analog and digital event data with the man-hours worked. The combined cause code events for both analog and digital display events trended down as well as the Total Man-hours Worked. The Total Human Error events category exhibited a stationary or flat trend line. During the research period the combined facilities "Man-hours worked" declined from 3,220,046 in 1995 to 2,247,800 in 2001. This representation indicated that there was 1 Human Error Event for every 67,084 man-hours worked in 1995 and 1 Human Error Event for every 44,956 man-hours worked in 2001. This data set supported the proposal that the per capita human error events were increasing. 


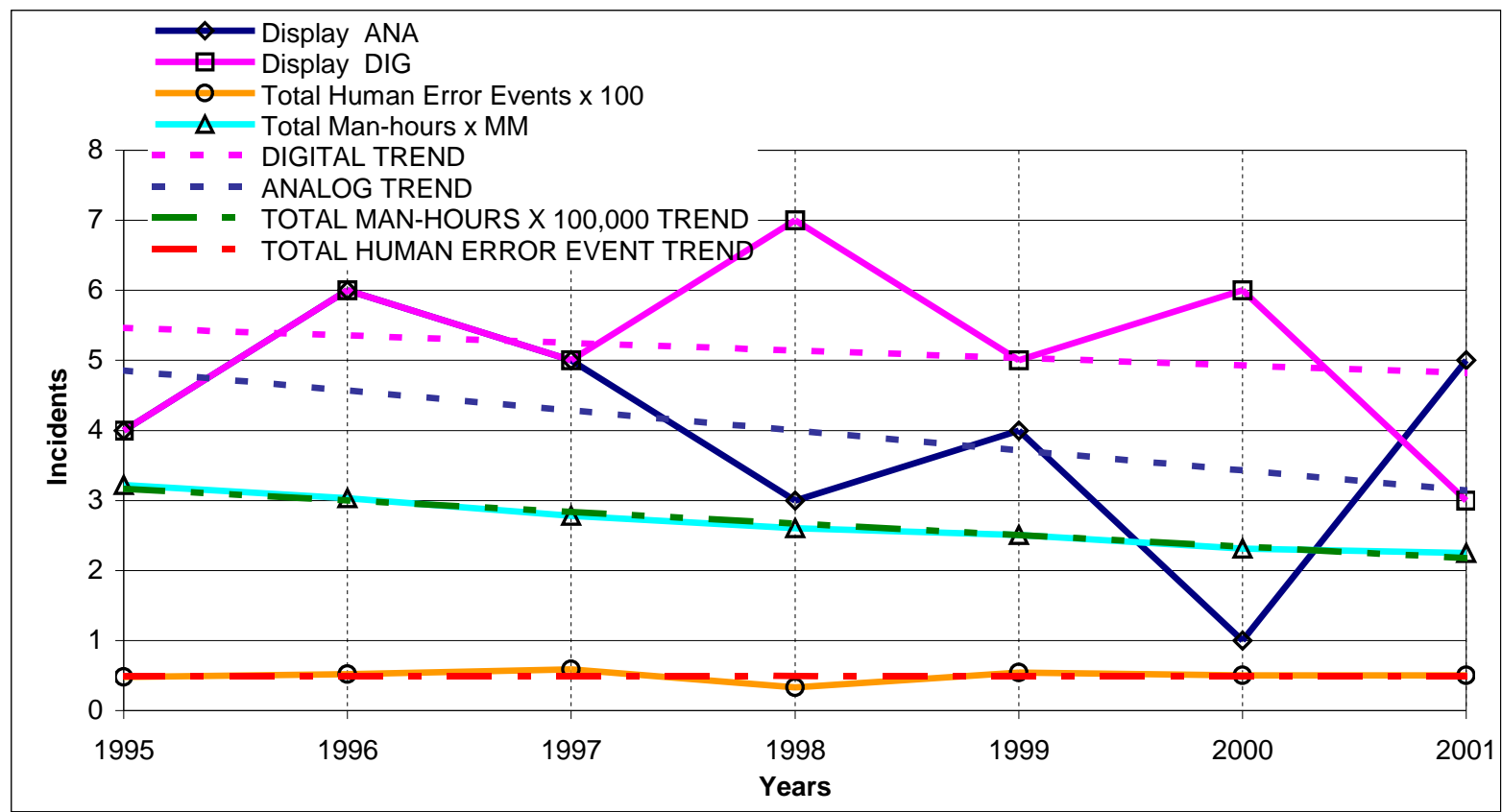

Note: $\mathrm{ANA}=$ Analog; $\mathrm{DIG}=$ digital $; \mathrm{MM}=100,000$

Figure 3. Combined Analog and Digital Incidents related to Total Human Error Events and Man-Hours.

Table 2 illustrates the raw data for Group "A." For reference, this table of data includes the "OSHA Recordable" incident events that occurred during research period. The "OSHA Recordable" incidents category indicated the number of events that were serious enough to qualify for recording or reporting in the OSHA $200 \mathrm{Log}$. These recordable incidents represent a range comparison of, from $25 \%$ to $45 \%$ of, the number of Human Error events. The "OSHA Recodables" were not used in the final analysis because the event records included both OSHA Recordable events and EPA Reporting events. Documentation was not consistently available for the EPA reported events. The event reports did indicate the area of impact for each event for categorization purposes. 
Table 2 data also displays the tabulated data for Analog events, Digital events, Manhours, and Human Error (HE) events that occurred during the study period. The Analog and Digital events combined in Group A for each individual year amount to less that $25 \%$ of the Human Error events. The Man-hours category in the Group A data indicated a sharp decline while the event categories remained stable for the period of study.

Table 2.

Group "A" Data

\begin{tabular}{|c|c|c|c|c|c|}
\hline \multicolumn{2}{|c|}{ Group A } & Recordable & HE Events \\
\hline & Analog & Digital & Man-hours x 1,000,000 & Ren \\
\hline \hline 1995 & 3 & 2 & 2.3130 & 17 & 37 \\
\hline 1996 & 4 & 4 & 2.1964 & 12 & 32 \\
\hline 1997 & 2 & 3 & 1.9410 & 9 & 46 \\
\hline 1998 & 3 & 4 & 1.7946 & 6 & 19 \\
\hline 1999 & 2 & 3 & 1.6917 & 11 & 26 \\
\hline 2000 & 1 & 3 & 1.4834 & 10 & 33 \\
\hline 2001 & 3 & 2 & 1.4568 & 10 & 41 \\
\hline
\end{tabular}

Figure 4 provides a graphic illustration of the relationship of Group A's individual OSHA Recordable events to the Human Error events. Trend lines indicated a slight decline in Group A's total recorable events as well as a decline in the Human Error events for the entire period of study. The declines in both categories indicated a relationship and a trend that on 
the surface appeared to be desirable. However, at this point in the analysis, the data in both categories were not linked to provide a true indication of the relationship.

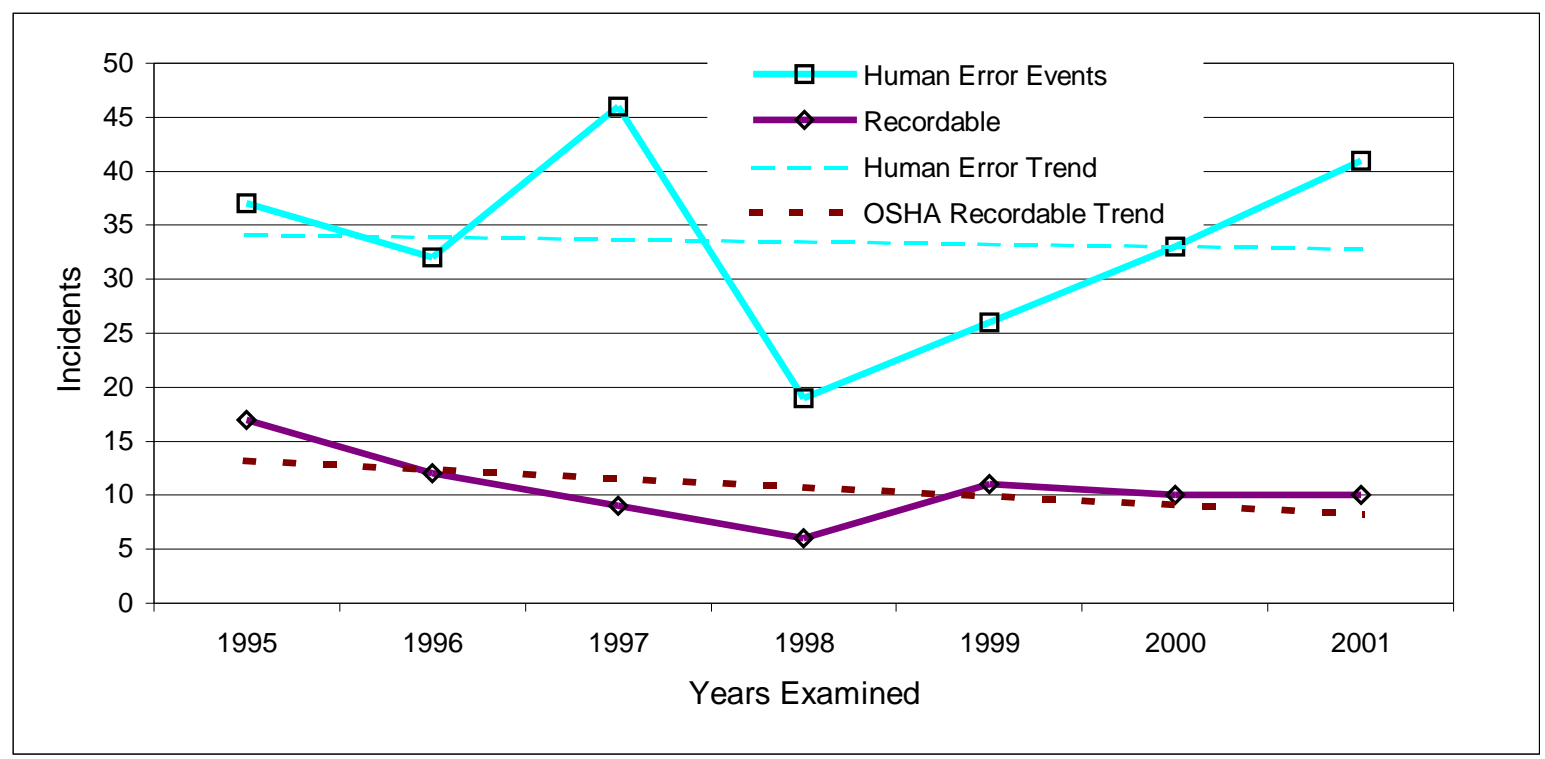

Figure 4. Group "A" OSHA Recordable Events Comparison with Total Human Error Events

Figure 5 illustrates the relationship of the Analog and Digital incident data in Group A to the man-hours worked during the study period. The data indicated that the number of analog and digital events declined during the research period. Figure 5 further indicated a decline in Man-hours over the study period that ranged from 2.3130 million man-hours in 1995 to 1.4568 million man-hours in 2001; a .85562 million man-hour decrease. Figure 5 also displays what appeared to be desirable trending, however the data is not factored properly to display the true incidence relationship. 


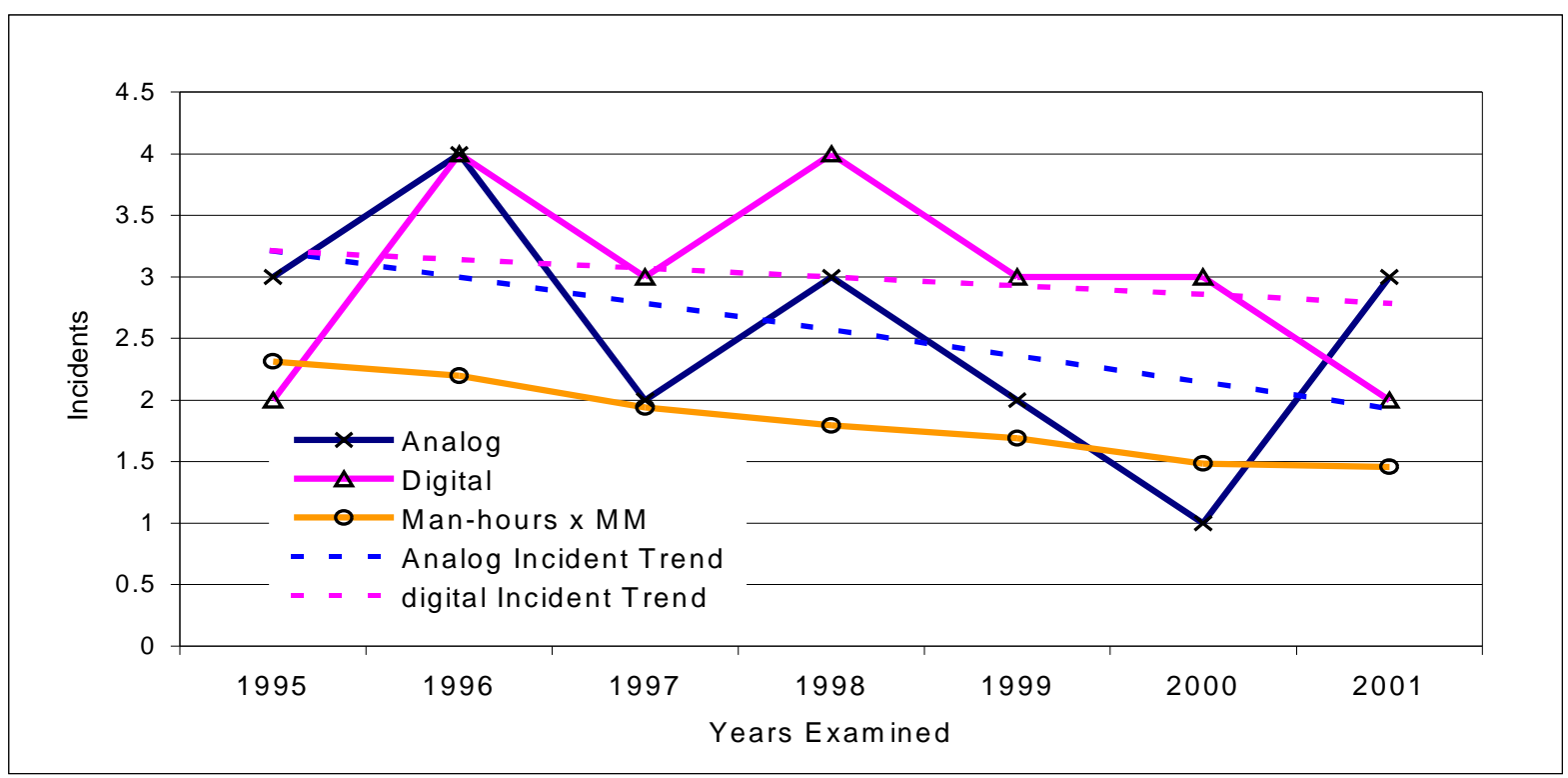

Note: $\mathrm{MM}=1,000,000$

Figure 5. Group "A" Analog/Digital Incident Comparison to Man-hours Worked

Table 3 illustrates the raw data recorded for Group "B" during the study period. This table includes the "OSHA Recordable" (Recordable) incident events that occurred during the research period for comparison and reference purposes. The "OSHA Recordable" incidents category presented in this chart indicate the number of events that occurred which were serious enough to qualify for recording or reporting in the OSHA $200 \mathrm{Log}$. These recordable incidents numbers indicate a comparative range from $42 \%$ to $71 \%$ of the number of Human Error events recorded. This comparison range was noted as 2 times the same comparable range of Group A. As in Group "A", the "OSHA Recordables" were not used in the final analysis because the event records included both OSHA recordable events and EPA Reporting events. 
Table 3 displays the tabulated data for Analog events, Digital events, Man-hour worked, and Human Error (HE) events. The combined Analog and Digital events for each year in Group B represent a range of $14 \%$ to $38 \%$ of the Human Error events.

Table 3

Group "B" Data

\begin{tabular}{|c|c|c|c|c|c|}
\hline \multicolumn{2}{|c|}{ Group B } \\
\hline & Analog & Digital & Man-hours x 100,000 & Recordable & HE Events \\
\hline \hline 1995 & 1 & 2 & 0.9070 & 6 & 11 \\
\hline 1996 & 2 & 2 & 0.8370 & 12 & 20 \\
\hline 1997 & 3 & 2 & 0.8420 & 9 & 13 \\
\hline 1998 & 0 & 3 & 0.8100 & 10 & 14 \\
\hline 1999 & 2 & 2 & 0.8170 & 12 & 28 \\
\hline 2000 & 0 & 3 & 0.8310 & 11 & 17 \\
\hline 2001 & 2 & 1 & 0.7910 & 5 & 9 \\
\hline
\end{tabular}

Figure 6 illustrates the relationship of the Human Error events to the total OSHA Recorded events in Group B. Trend lines indicated that there was a slight decline in the Group B's total recorable events and an incline in the trend line for Human Error events. 


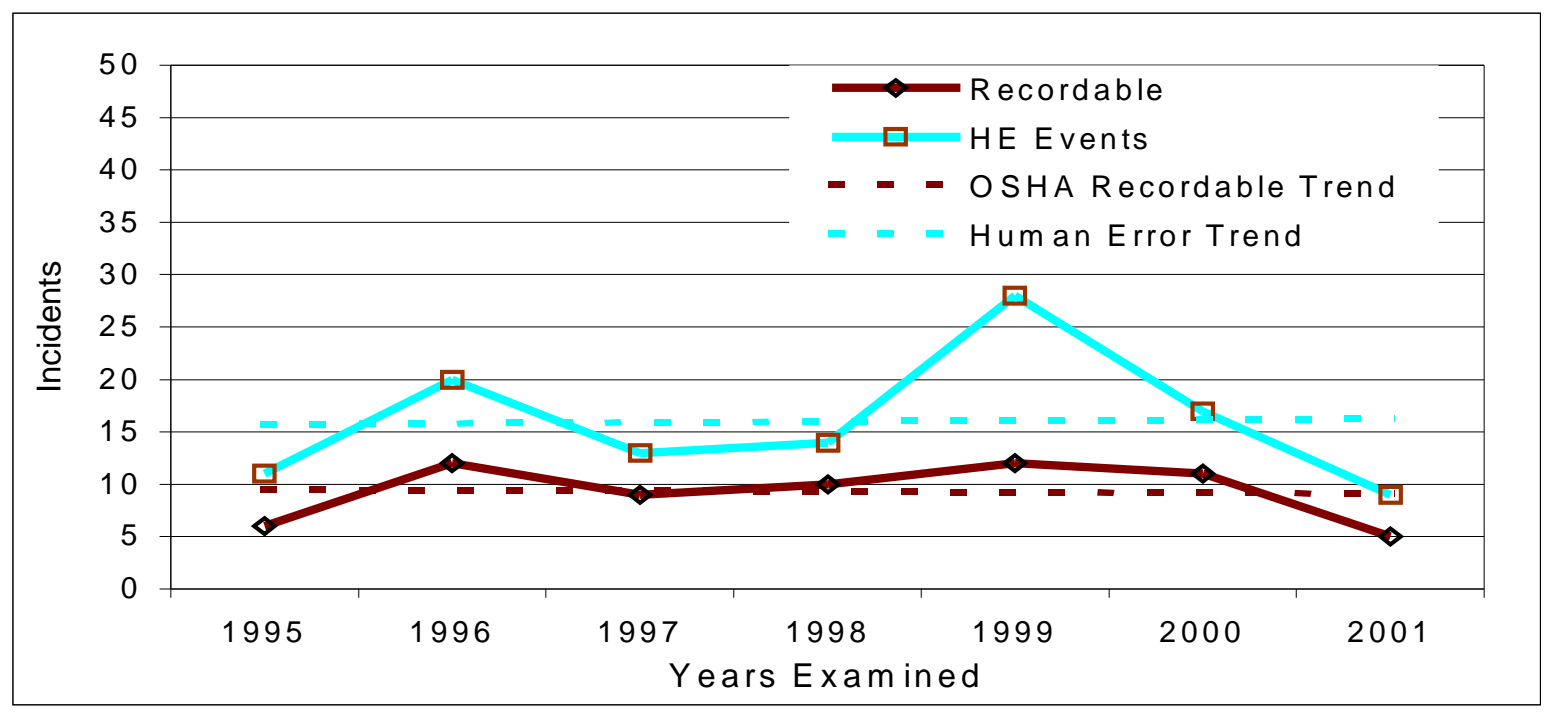

Note: Trend lines for each data group are illustrated as dashed. HE = Human Error Events.

Figure 6. Group "B" OSHA Recordable Incidents Compared to Total Human Error Events.

Figure 7 illustrates the relationship of the Analog and Digital event data in Group B to the man-hours over the study period within the same group. The trend at this scale indicated the number of analog and digital events during the research period declined slightly. Figure 7 also illustrates a slight decline of Man-hours over the study period for Group B from .9070 million man-hours in 1995 to .7910 million man-hours in 2001; a .1160 million man-hour decrease. The data presented for Figure 7 illustrated a graphic contrast between Analog and Digital incidents in the years 1998 and 2000. 


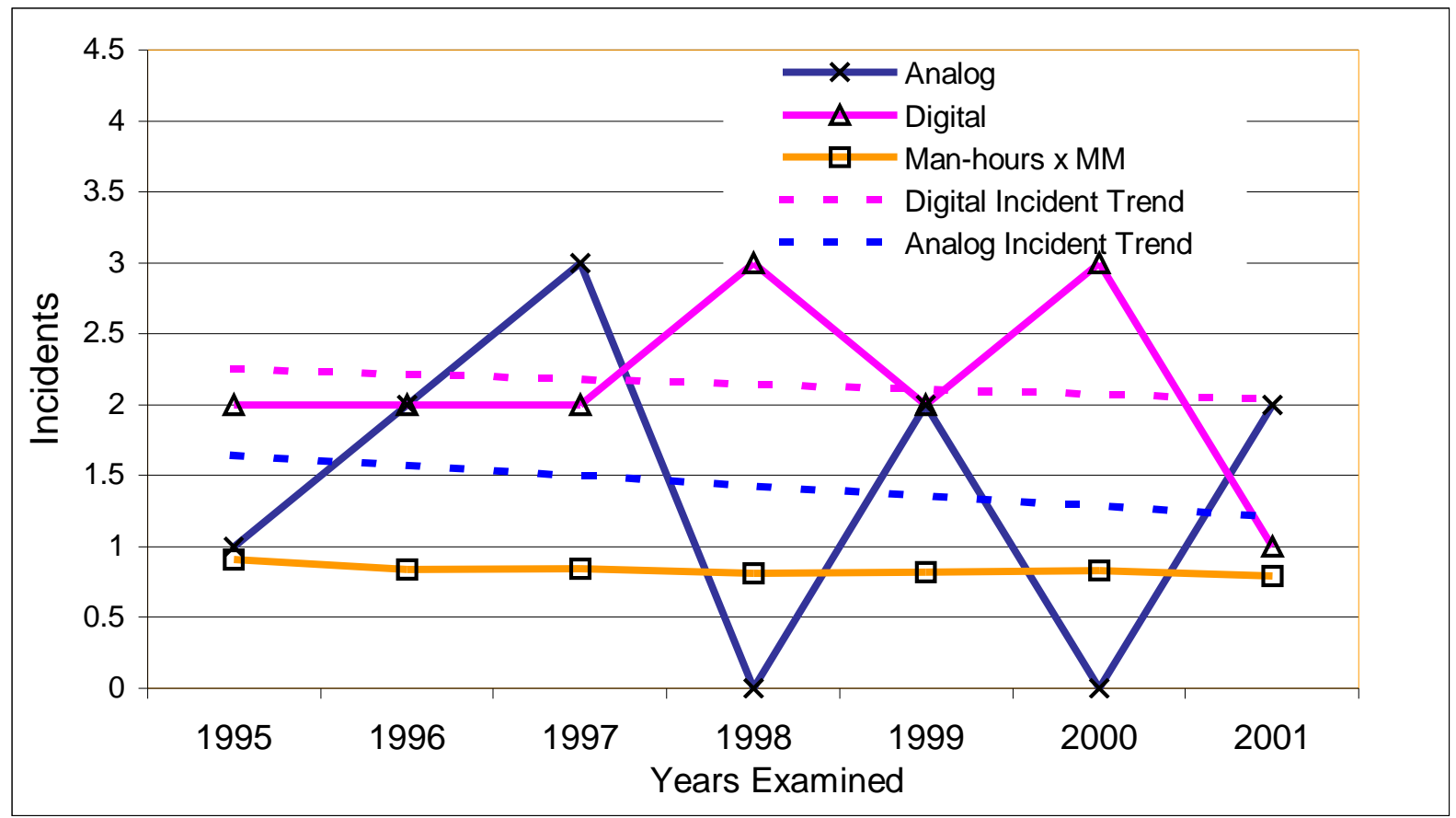

Note: $\mathrm{MM}=1,000,000$

Figure 7. Group "B" Analog/Digital Incident Comparison to Man-hours Worked

Figure 8 provides a comparison of Analog and Digital incidents to the total recorded incidents reviewed for Group A. A trend line was provided on this figure to illustrate a decline in the total recorded events during this research period. It should be noted that Group A was the group that exhibited the greatest decrease in man-hours over the research period. This suggested that the total declining recorded events and the total man-hours for the same research period may have influenced each other. However, as these two categories indicated declining trends, analog and digital incidents remained relatively the same. 


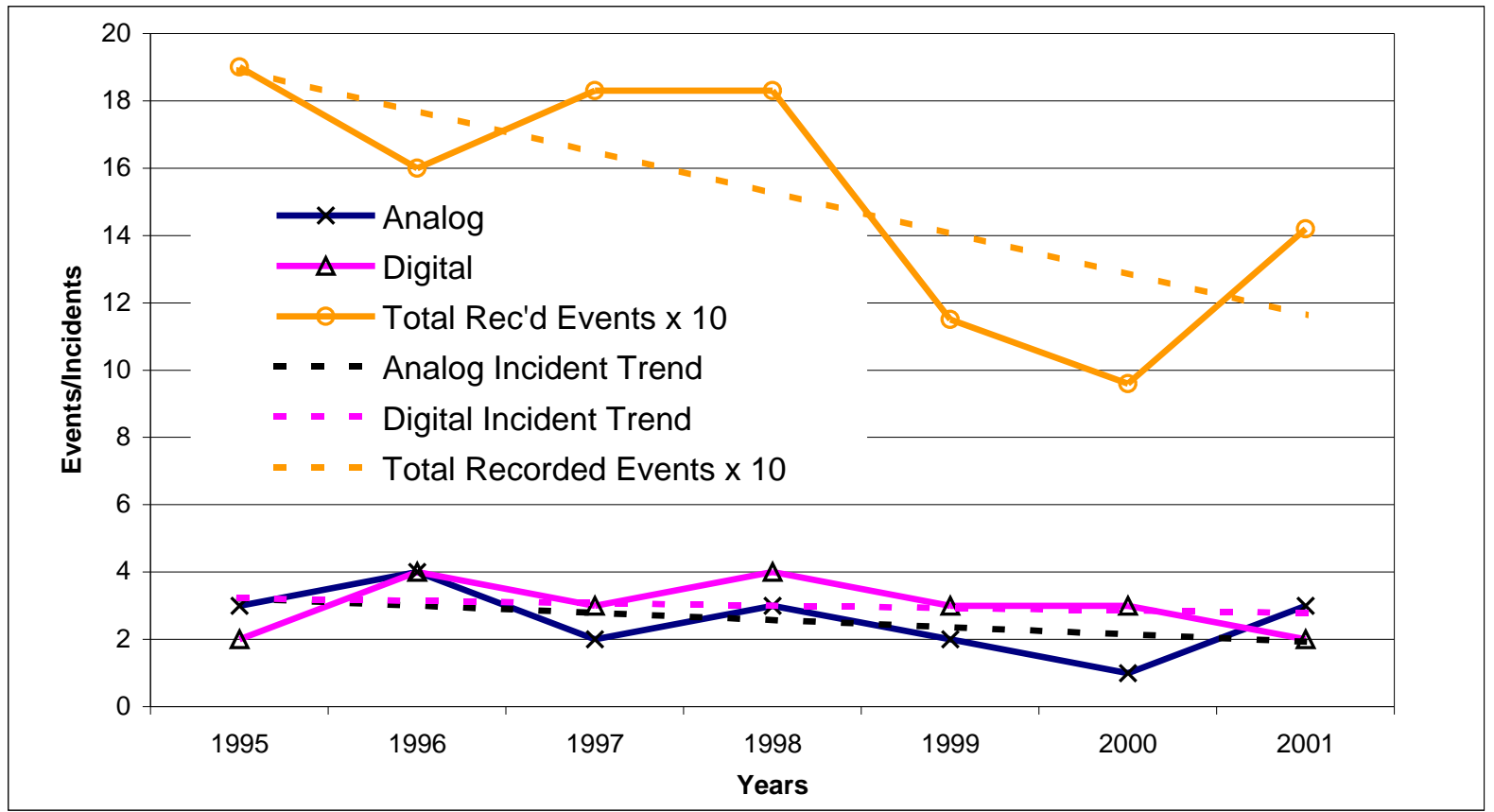

Note: Trend Lines for each data group are illustrated as dashed.

Figure 8. Group "A" Analog/Digital Incidents versus Total Incidents Reviewed

In contrast to Figure 8, Figure 9 illustrates a trend line that was inclining for the total recorded events in Group B. The exhibited decline in man-hours for Group B (Figure 7), as previously noted, indicated that even though the man-hours were declining, the total recorded events were increasing, while the number of analog and digital events remained relatively the same.

This indicates two things; 1 Group B was experiencing a higher per capita incident to man-hour relationship, and 2 even though the analog and digital event numbers remained steady the ratio of analog and digital to man-hour events was also increasing. 


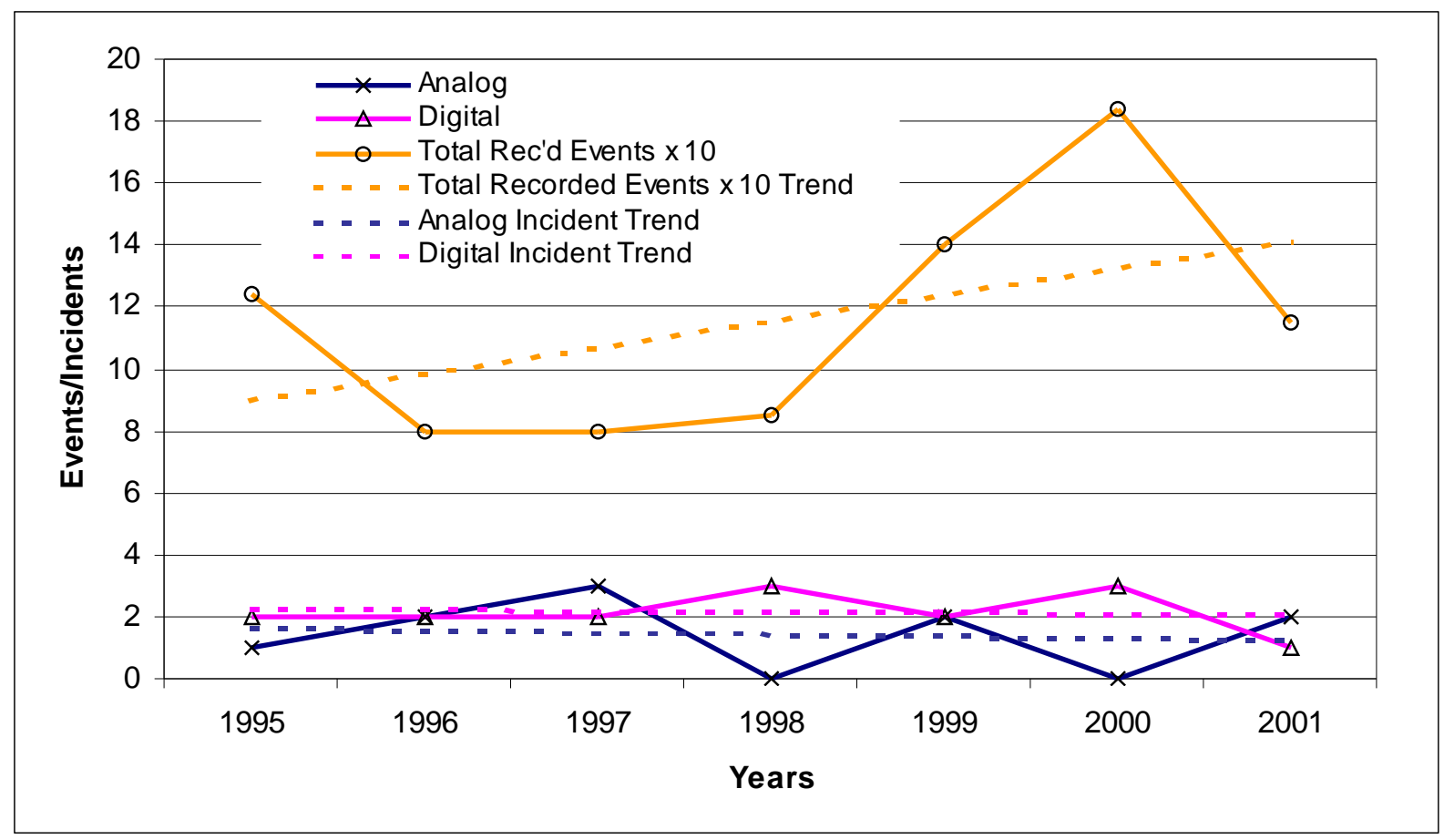

Note: Trend Lines for each data group are illustrated as dashed.

Figure 9. Group "B" Analog/Digital Incidents versus Total Incidents Reviewed

Figure 10 illustrates the analog and digital incidence rates compared to the total manhours for the duration of the research period for Group A. A trend line was not provided for the total man-hour graphic because the indication was self-explanatory. However, trend lines for the analog and digital incidence rates were provided to illustrate that each of these categories suggested a positive or upward trend. It should be noted that, in Figure 8 the analog and digital incident events did not indicate a very large positive or negative trend, although the analog incidents events did suggest a slight decline. As discussed earlier in the narrative related to Figures 4 and 5, the incident trends appeared to be indicating a good trend, but were not properly factored with reference to the man-hours worked. 
The analog and digital "incidence rate" (a factor of the number of incidents and the man-hours worked) in both cases suggested an incline or increase over the research period. Since the incidence rate in Figure 10 was a function of the total man-hours, any change in either category directly affected the other associated indicators. Figure 10 provides a graphical representation indicating that both the Analog and Digital incidence rates were trending up.

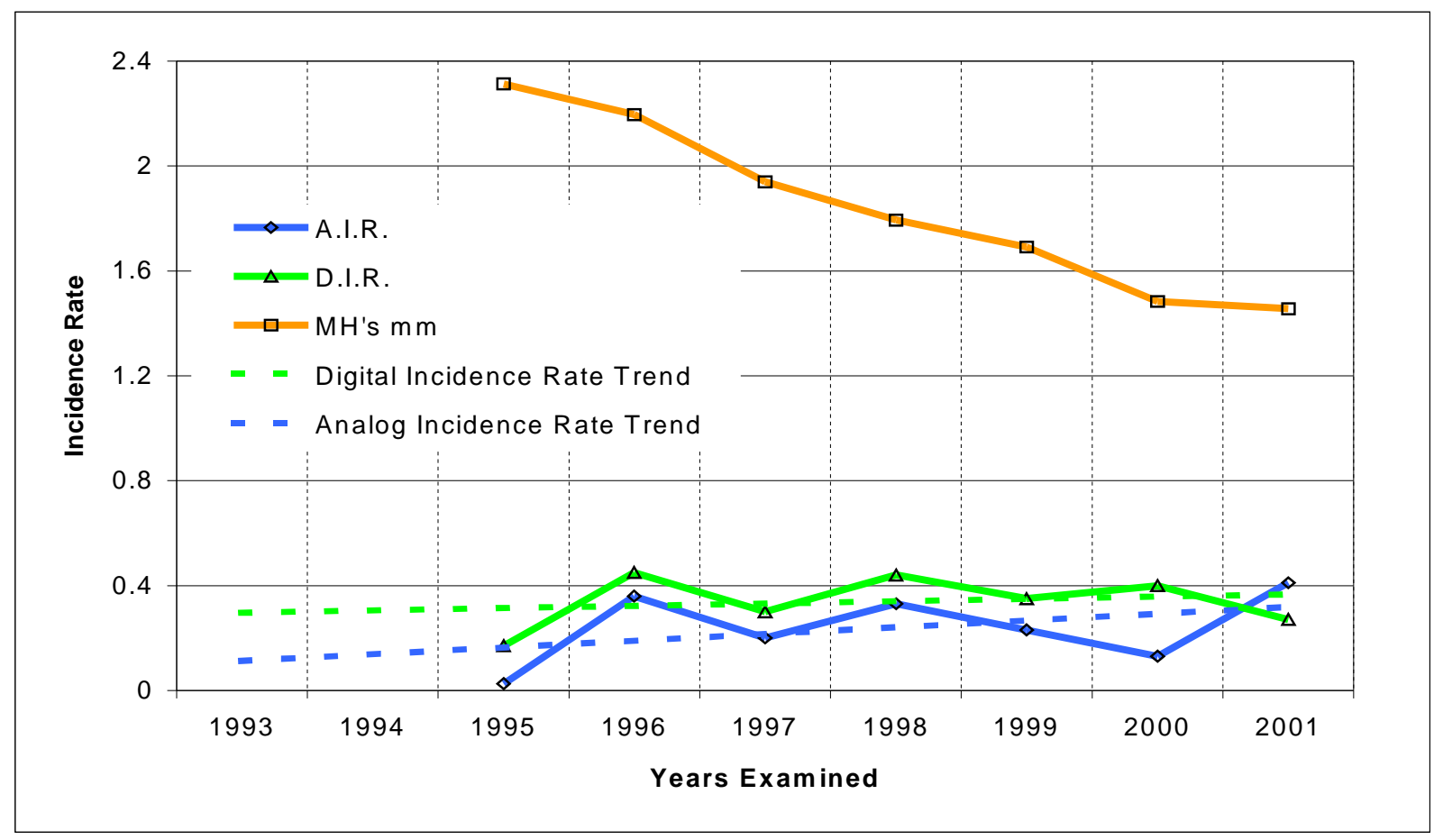

Note: A.I.R. $=$ Analog Incidence Rate, D.I.R. $=$ Digital Incidence Rate

Figure 10. Group "A" Analog/Digital Incidence Rate/Man-hour Comparison.

Figure 11 illustrates the analog and digital incidence rates as compared to the total man-hours for the duration of the research period for Group B. A trend line was not provided for the total man-hour graphic because the indication was self-explanatory. However, trend lines for the analog and digital incidence rates were provided to illustrate that each of these 
categories suggested a downward and level trend respectively. It should be noted that, in Figure 9 the analog and digital incident events did not indicate a very large positive or negative trend although the analog incidents events did suggest a slight decline. The analog and digital incidence rates in both cases in Figure 11 suggest a decrease and leveling respectively over the research period. The incidence rate in Figure 11 is a function of the total man-hours; therefore any change in either category directly affected the other associated indicators.

The data in Figure 11 indicated that the per capita incidence rate for Analog related incidents trended down or decreased while the Digital per capita incidence rate remained level.

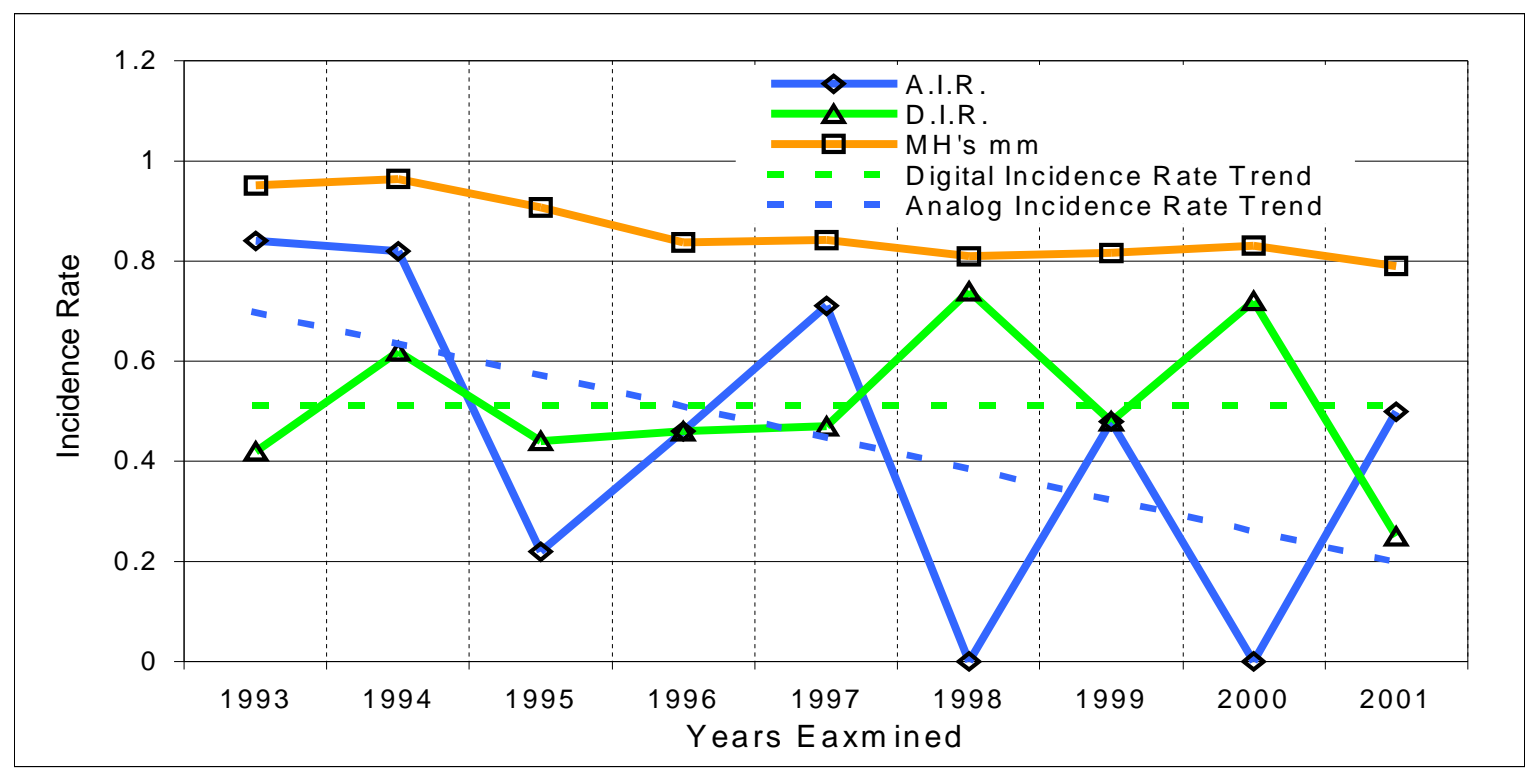

Note: A.I.R. = Analog Incidence Rate, D.I.R. = digital Incidence Rate

Figure 11. Group "B" Analog/Digital Incidence Rate/Man-hour Comparison 


\section{Events Summary}

Table 4 illustrates "Incidence" data for Group A. The four columns represent event data that was calculated using the man-hours worked for the years indicated. Data used from the Bureau of Labor Statistics (BLS) in column 1 was complete up to and including the year 2000. No data was available for the year 2001.

Table 4

Group "A" Incidence Data

\begin{tabular}{|c|c|c|c|c|}
\hline & BLS Rate & Group Rate & Analog & Digital \\
\hline & & & & \\
\hline 1995 & 4.9 & 1.47 & 0.025 & 0.17 \\
\hline 1996 & 4.3 & 1.09 & 0.36 & 0.45 \\
\hline 1997 & 3.9 & 0.93 & 0.2 & 0.3 \\
\hline 1998 & 3.4 & 0.67 & 0.33 & 0.44 \\
\hline 1999 & 4.3 & 1.30 & 0.23 & 0.35 \\
\hline 2000 & 3.5 & 1.35 & 0.13 & 0.4 \\
\hline 2001 & nd & 1.37 & 0.41 & 0.27 \\
\hline
\end{tabular}

(Bureau of Labor Statistics, 2000)

The data in Figure 12 indicated that, for Groups A's Standard Industry Code (SIC Code), the industry's safety incidents as a whole were declining. The inference was that, over the period of the study, more OSHA Recorcable events occurred per man-hours worked. Another way to interpret this data was that, even if the raw incident numbers for either/both the Analog or Digital Display events remained the same, the incidence rate would increase as long as the man-hours continued to decrease. 
Data did not exist in the BLS database regarding display-related events nor did it exist for human error events in general. However, based on the data presented in Table 5, within a range of $0 \%$ to $16 \%$ of all OSHA recordable events, there would be 1 display related event for this SIC code industry category.

The large graphical gap between the BLS incidence rate line and Group A's incidence rate indicated that Group A, from an industry comparison standpoint, had experienced less than half of the normal industry recordable incidences. They had a better safety record overall than others within their respective industry classification.

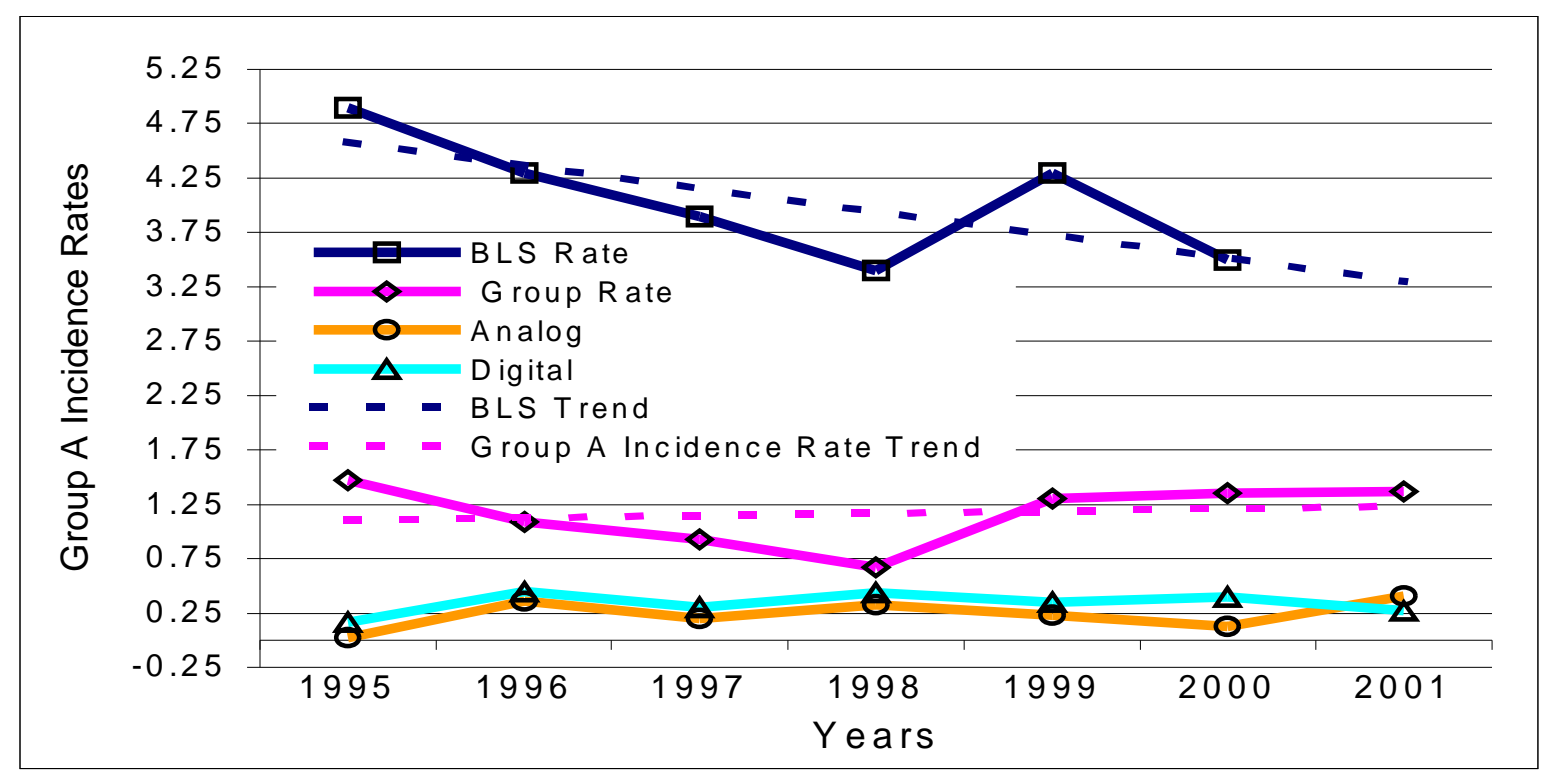

(Bureau of Labor Statistics, 2000) Note: BLS = Bureau of Labor Statistics

Figure 12. Summary Comparison of Bureau of Labor Statistics (BLS) Data and Group "A" Data.

Table 5 illustrates "Incidence" data for Group B. The four columns represent event data that was calculated using the man-hours worked for the years indicated. Data used from 
the Bureau of Labor Statistics (BLS) in column 1 was complete up to and including the year 2000. No data was available for the year 2001.

The data for Table 5 and Figure 13 provided an illustration of a summary comparison of data for Group B with regard to Group B's Standard Industry Classification Code (SIC). Table 5 indicates that Group B's OSHA Recordable incidence rates were at or below the BLS Incidence rate for Group B's SIC Code. Figure 13 below provides a graphical representation indicating the close proximity of the Incidence Rates.

Table 5

Group B Incidence Data

\begin{tabular}{|c|c|c|c|c|}
\hline & BLS Rate & Group Rate & Analog & Digital \\
\hline \hline & & & & \\
\hline 1995 & 3.3 & 1.32 & 0.22 & 0.44 \\
\hline 1996 & 2.9 & 2.87 & 0.46 & 0.46 \\
\hline 1997 & 4.3 & 2.14 & 0.71 & 0.47 \\
\hline 1998 & 2.5 & 2.47 & 0 & 0.74 \\
\hline 1999 & 2.9 & 2.94 & 0.48 & 0.48 \\
\hline 2000 & 2.7 & 2.65 & 0 & 0.72 \\
\hline 2001 & $\mathrm{nd}$ & 1.26 & 0.5 & 0.25 \\
\hline
\end{tabular}

(Bureau of Labor Statistics, 2000)

Figure 13 illustrates that, for Groups B's SIC Code, the industry as a whole was declining, in a manner similar to the Group Rate category in Figure 13. This was interpreted as fewer OSHA Recorcable events per man-hour worked. Figure 13 also indicates that the incidence rate for OSHA Recordables for Group B was trending up very slightly, since there 
were more incidences per man-hour worked. Data did not exist in the BLS database regarding display-related events, nor for human error events in general. Based on the data presented in Table 5, it was found that within a range of $0 \%$ to $16 \%$ of all OSHA recordable events, there was 1 display related event for this SIC code industry category.

The relatively small gap represented in Figure 13 between the BLS incidence rate for Group B's SIC Code and Group B's incidence trend, indicated that Group B's incidence performance over the study period was at, or just below the BLS rate for SIC code industry category.

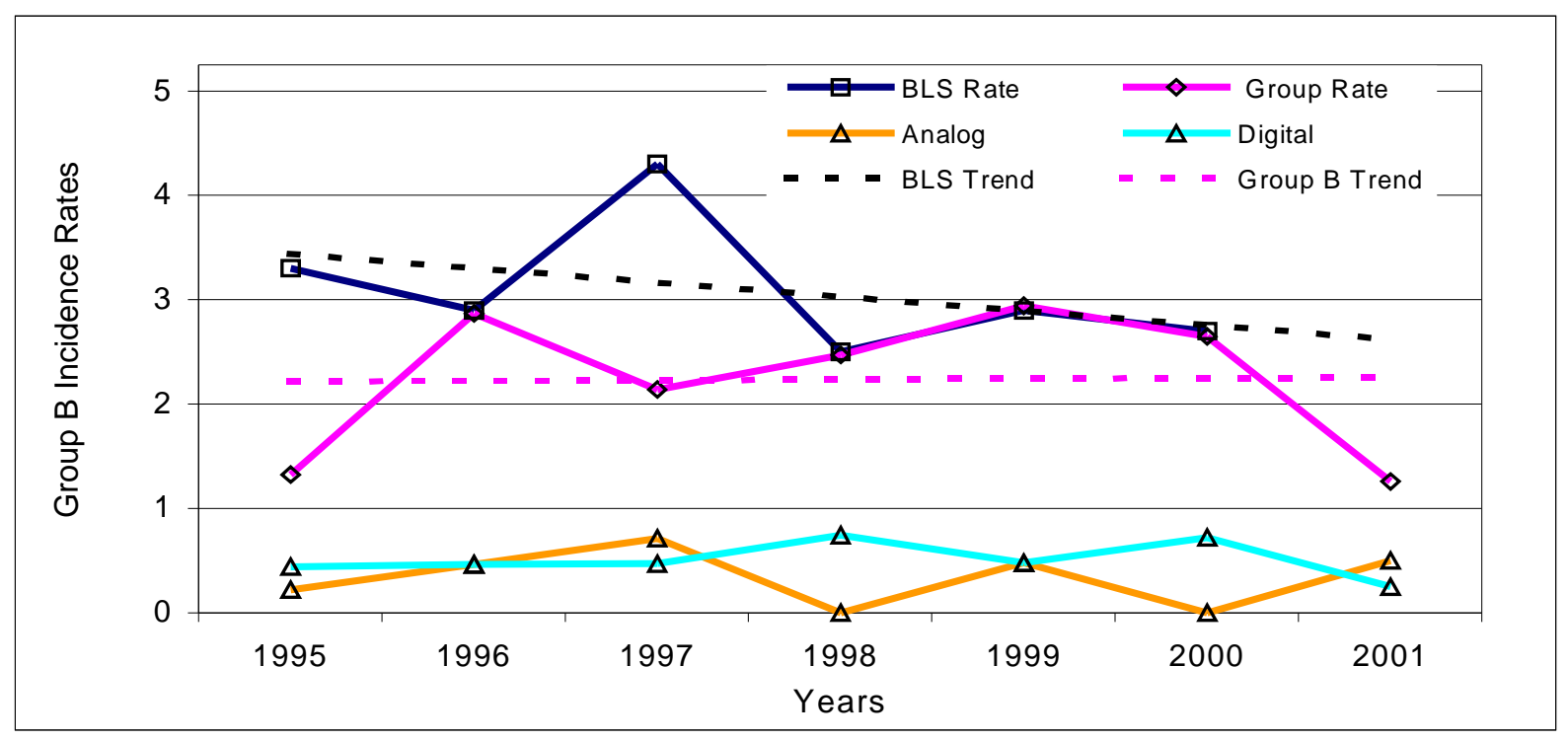

(Bureau of Labor Statistics, 2000) Note: BLS = Bureau of Labor Statistics

Figure 13. Summary Comparison of Bureau of Labor Statistics (BLS) Data and Group "B “ Data. 


\section{CHAPTER V}

Summary, Findings, Conclusions, and Recommendations

\section{$\underline{\text { Problem Statement }}$}

The problem of this research was to determine the impact the transition from analog to digital process display gauges had on the safety incidence rate relating to human error frequency in the chemical industry.

\section{Summary}

The belief that analog display gauges in the chemical industry were being replaced by digital display gauges because they were faster than analog displays, more accurate, and provided a safer operational environment provided the direction and purpose for this research. The collection and examination of the data for this research yielded several fundamental findings and conclusions regarding human error as related to analog and digital display gauges within the chemical industry.

\section{$\underline{\text { Statistical Observations }}$}

The final analysis of the presented data did not establish the validity for the null hypothesis with regard to the Digital Incidence Rates and the Combined Incidence Rates. The Null Hypothesis stated that: The transition from analog to digital display gauges, in the chemical industry, had no impact on the safety incidence rate at a .05 significance level, was however validated for the Analog Incidence Rate. 
A one-way ANOVA (See Tables 6 and 7) was conducted on the individual groups;

Group A and Group B. No significant difference was found $(F(1,12)=0.726>.05)$ for the Analog Incidence Rate. However significant differences were found $[(\mathrm{F}(1,12)=$

$5.063<.05),(\mathrm{F}(1,12)=8.380<.05)]$ for the Digital Incidence Rate and the Combined Display Incidence Rates respectively.

In Tables 6 and 7, the "F values" indicated that the null hypothesis was verified for the Analog Display Incidence Rate, or that there was no significance at the .05 level. The " $F$ Value" for the Digital Display Incidence Rate and the Combined Display Incidence Rate, however, was significantly greater than 1 , indicating that there was more variation between groups than within groups. This condition indicated that the null hypothesis was not valid and that the Digital Incident Rates as well as the Combined Display Incidence Rates had a significant affect on the overall safety incident rate.

Table 6

Analysis of Variance for Analog Incidence Rates and Combined Display Incidence Rate

\begin{tabular}{|c|l|c|c|c|c|c|}
\hline & & Sum of Squares & df & Mean Square & F & Sig. \\
\hline \multirow{2}{*}{$\begin{array}{c}\text { Analog Incidence } \\
\text { Rate }\end{array}$} & Between Groups & 0.033 & 1 & 0.033516071 & 0.726 & 0.410 \\
\cline { 2 - 8 } & Within Groups & 0.553 & 12 & 0.046125595 & & \\
\cline { 2 - 8 } & Total & 0.587 & 13 & & & \\
\hline \hline \multirow{2}{*}{$\begin{array}{c}\text { Combined Display } \\
\text { Rate }\end{array}$} & Between Groups & .215 & 1 & .215 & 8.380 & .013 \\
\cline { 2 - 8 } & Within Groups & .308 & 12 & 0.02569 & & \\
\cline { 2 - 8 } & Total & .524 & 13 & & & \\
\hline
\end{tabular}


Table 7

$\underline{\text { Analysis of Variance for Digital Incidence Rates and Combined Display Incidence Rate }}$

\begin{tabular}{|c|c|c|c|c|c|c|}
\hline & & Sum of Squares & df & Mean Square & $\mathbf{F}$ & Sig. \\
\hline \multirow{3}{*}{$\begin{array}{c}\text { Digital Incidence } \\
\text { Rate }\end{array}$} & Between Groups & 0.099457143 & 1 & 0.099457143 & 5.063 & 0.043 \\
\hline & Within Groups & 0.235685714 & 12 & 0.019640476 & & \\
\hline & Total & 0.335142857 & 13 & & & \\
\hline \multirow{3}{*}{$\begin{array}{c}\text { Combined Display } \\
\text { Rate }\end{array}$} & Between Groups & .215 & 1 & .215 & 8.380 & .013 \\
\hline & Within Groups & .308 & 12 & 0.02569 & & \\
\hline & Total & .524 & 13 & & & \\
\hline
\end{tabular}

\section{Data Review}

The data gathered for this research provided an opportunity to compare and contrast the subject group's recordkeepng procedures and evaluate the nature of their occurrences. The numerical range of recorded events for both groups reviewed was from 190 per year at the upper limit to 80 per year at the lower limit. The "Display Event" data represented a relatively small but significant portion of the total safety/environmental incidents records.

During the data collection efforts it was discovered that incident remediation processes were initiated after the events had occurred. This included, but was not limited to, documented follow-up training and/or instruction in almost every case. The instruction and training comments in the follow-up reports suggested that there was a well-established retroactive program to address problems as they occurred.

Table 1 listed data most relevant to this research. The key data categories displayed in Table 1 for the combined group results in the research years examined included the following:

- The years the research data represents. 
- Display related Incidents for both Analog and Digital displays.

- Man-hours worked for the years represented.

- The total "Human Error" type events/incidents that the records indicated.

- Cause Codes for the years represented.

- Incidence rates for Analog and Digital Incidents as well as Human Error events.

\section{$\underline{\text { Analog and Digital Displays }}$}

The incident reports from the group facilities did not have specific form categories for display related events. The reports did however provide a check box or an area category in the form for the explanation for any event that was regarded as a "Human Error". Detailed examination of each of these human error indicated events provided information that allowed for a determination of the type, if any, of display involved in the event. The narrative section of the reports provided further insight into determining the cause code category. The report narrative in combination with data from engineering records, process area visits, and some follow-up questions for clarification provided background information for categorizing the events. As previously noted the analog display instruments tended to be located in the immediate vicinity of the equipment that was being monitored and the digital display instruments tended to be located in a control area or a location removed from the process equipment being monitored.

During the process of clarifying histories and engineering approaches to display installations, engineers at the Group A facility stated that there had been an effort to standardize the display panel color codes and operational display color sequences. This standardization would provide a basis for standardized training for all production operators 
and permit operators the flexibility to go from one operating unit to another with minimal impact in the interpretation of displays.

\section{$\underline{\text { Man-hours }}$}

The years represented in the research data were years that had complete records for each month of that particular year. Group B's records were complete for two additional years (1993 and 1994) but these years were not included in the analysis because Group A's records were not complete during the same period. The man-hours for the combined groups dropped by approximately 1 million hours over the entire study period. Each group indicated a trend that was consistent with all major manufacturing industries for the past 15 years (BLS, 2000). This drop reflected an industry-wide trend that has plateaued as of the end of 2001. Several factors including the general economic downturn, automation of processes, and the general shifting of product manufacturing bases (foreign production of same or similar products) contributed to the man-hour decline.

Group A's raw man-hour rate was twice the man-hour rate of Group B for the study period. The tabulated man-hour rate included the hours worked for all personnel that worked at the facility during the year represented. Work hours for construction activities at the plants were not included in the totals.

Group A reported man-hours to the nearest hour and Group B reported man-hours to the nearest 1,000 hours. Both groups gathered worked hours from payroll records and used their individual rounding methods to prepare reports required OSHA. 


\section{$\underline{\text { Total Events on Record }}$}

The combined total events (not shown in Figure 1) on record suggested that diligence existed for the recording and "follow-up" of any event that appeared to be out of the ordinary from a process, environmental, or safety standpoint. There existed a level of cooperation and communication between production personnel, environmental personnel, and the safety personnel functions at each of these facilities that was essential in this data recording effort. The records examined at these facilities exhibited a range of events from minor cut/bruises and other non-events, such as behavioral problems with no resulting injury or process upset, to very serious conditions such as those requiring emergency transport or evacuation. This attention to detail further verified the level of effort present for addressing and preventing incidents observed in the facility reports

The combined data revealed a recorded total of 1812 entries in the incident records. Of these 1812 events, 346 were designated as Human Error incident events for the research period. Of the 346 human error events, 64 events on record were categorized as either analog or digital display related. The 64 recorded events and incidents represented $3.5 \%$ of all recorded events over the study period.

\section{$\underline{\text { Total Human Error Events }}$}

The incident reports provided sufficient detail to designate and specify categories for Human Error events. This specific information, included on the report forms, along with the narrative provided insights into the event types. The information further aided in the narrative review of other events to determine if they too may have qualified for the display related categorization under the format of this study. Several cases were discovered and categorized 
as display related events that were not originally marked as "Human Error" on the incident report form.

During the incident report investigation it became apparent that several Human Error designated events shared similarities with other reviewed events. These cases appeared to share a commonality for both type and process location throughout the study period years. The "common" or similar events in some cases were exact repeats of previous events in the same operating area. To assure thoroughness, events that appeared to be similar or repeated were further investigated in order to verify that records had not been misfiled or recorded again.

Root causes for the events that shared common characteristics fell into two categories. The first category of common events was where the operators involved in the incident were assigned to the production area on a temporary basis and did not have a familiarity with the processes involved. The second general category of root causes focused on a change in processes within an operating unit. These changes included the installation of new equipment, different specifications (recipes) to an existing process, start-up after a long maintenance shutdown, and operators returning from a long break.

\section{$\underline{\text { Trends }}$}

Figure 1 provided a visual reference to the combined incidence rates. Trend lines in Figure 1 clearly depict an upward trend in the number of Human Error Events and Man-hour rate declines over the same period of time. The analog and digital events were included in the Human Error events category. When set apart from the Human Error events, the combined analog and digital incidence rate remained on a relatively even level. 
Figure 2 provided a combined display incident graphic where the incidents were separated into the individual Cause Codes. The incidents in Figure 2 were charted as the actual count of incident events. Two of the four categories indicated a downward trend and two indicated an upward trend. Notably, Figure 2 depicted a trend rise in the cause code labeled "FR" or Failure to Respond. The Cause Code, Failure to Respond, was generally described in the event narratives as (paraphrased) “... operator took too long to respond ..." or "... operator was waiting for something else to happen in conjunction with ...".

The associated "FR" trend line in Figure 2 suggested a validation of P.S.E. Farrell's (1999) "Response Lag" hypothesis for the potential explanation of what would happen in a "sampling strategy phase" of the decision making process. The trend indicated that the operators were waiting, analyzing, comparing, and or procrastinating as to the next course of action while observing an instrument indication, and in the course of doing so forfeited the opportunity to provide the proper response. Again this was further verified in the associated report narratives.

It was found that the category "IH" in Figure 2 or Implied Human Error trended down over the same period. This particular down trend indicated that, the report originator or incident investigator, rather than select a "Catch All" category, such as Implied Human Error, became better at assigning more germane causes to incidents. The Figure 2 trend further indicated a departure from Hollnagel's (2001) hypothesis in which he suggested that it had become cheaper to or more convenient to put the blame on human error.

Figure 3 actual count data indicated that as a combined group all human error related events were declining. The man-hours data also exhibited a downward trend. The presentation of the actual count data in this charted form was not factored with the man-hours 
for clarity. The clarity in this graphic provided a focus on specific events for specific associated dates that were otherwise skewed in the combined incidence figures. The data in Figure 3 provided a visual relationship for combined analog and digital display incidents and the human error event trend.

Individual group trends were represented in Figures 4 through 13 in order to provide "within group" comparisons to Bureau of Labor Statistics data and incidents factored by manhours to generate incidence rates for individual variables.

\section{$\underline{\text { Findings and Conclusions }}$}

The conclusion that was drawn from the findings of collected data summarized above was that the transition from analog to digital displays made a significant negative impact in the safety incidence rates in the chemical industry at the .05 level. The negative impact was that digital display related events were a significant causal factor in the increase of the total human error events. The total combined display related events were also a significant causal factor in the increase of then overall safety incident rate.

The research groups were considered to be typical within the chemical industry. The Standard Industry Code (SIC) incidence rates associated with the study groups suggested that the study groups fell within a range that was average to below average (better than) of the normal level when compared to the chemical industry, within the same manufacturing SIC designation.

The relationship of display related incidents was then theoretically protracted to the other manufactures within the SIC code and to the chemical industry in general. This would generally imply that $3.5 \%$ of all incidents were display related. It was further concluded from 
this research that within the $3.5 \%$ of display related events there was a significant number of digital display related events that contributed to the total incidence rate.

Initially the $3.5 \%$ of total incidents did not appear to be a worrisome percentage and indeed appeared to be completely overlooked or ignored as a significant contributor. It should be noted however, that when an event in a chemical plant does occur the effects could be disastrous. Tewksbury, Bhopal, Institute, and Three Mile Island (Nuclear Power Plant) are a few examples of notable occurrences in which human error with regard to display misinterpretation have been suggested at some level of operation as a contributing factor.

Implications with regard to the various trend lines clearly established that demands on the process operators were increasing, and the emphasis to complete more tasks in smaller allotted time was evident. To exacerbate and possibly amplify potential problem effects, the frequency of the training program was reported as not being consistent. Comments by plant personnel were repeated in both groups to the effect of that they knew they needed to do a better job with training.

A secondary conclusion (and possibly the most important) was that more tasks were being assigned to fewer operators. Although the display related incident rate was the focus of this research, the increase in the number of required tasks provided a catalyst for incident causes in other categories such as slips and falls, hand cuts, and improper lifting and carrying. Although environmental conditions clearly contributed to these kinds of incidences, human error or behavior was often overlooked as the root cause.

The incident reports in the documented research occasionally provided narratives in the follow-up portion of the report describing proper task steps for the normal operation of the 
involved processes. The reports implied but did not cite operator behavior as a contributor due to the number of process tasks being performed.

The final analysis suggests that relevant and consistent operator training programs could reduce and in some cases eliminate the frequency of human error display related events.

\section{Concluding Comments/Observations}

To enhance program development, designers and engineers should consider all available resources when considering specific systems for automation. A major resource is the incident reports themselves. As narratives in the reports and overall investigations become more thorough they could provide a valuable insight into the operational conditions and behaviors of the operators in both normal and upset operating conditions.

Another valuable resource to be integrated into the initial developmental process is the vendors or suppliers of the automated technology and equipment. Quality in this selection cannot be overlooked. The vendors will typically sell anything that seems to fit the process without a great deal of process knowledge. They will also provide a cursory training program specific to the instrument or technology that they are selling. Often for proprietary reasons vendors and systems designers do not know the intricacies of the involved processes and do not know the operator skill level. This situation will handicap the training from the "well meaning" vendor's standpoint.

This brings up a third and most important consideration for system design with reference to operator functions. This is the training consideration. As previously noted, incident reports are an excellent resource for designing the training scenarios for individual processes. In considering training it will be important to review past process histories from 
production and safety points of view. Training scenarios and exercises should be designed to duplicate the process and the operator environment as closely as possible.

A final suggestion would be to standardize operational processes related to displays as much as possible. In discussions with personnel this was recognized and being implemented to some extent. The standardization of instrumentation display and training would be recommended priorities.

This research did not visit the proactive training aspect of the incident remediation within the group's facilities. During the investigations statements from various personnel provided insight into the training programs and indicated that there was a current inadequacy in this area, or at least opportunities for improving training modules across the training spectrum.

\section{Training Assessment Methods}

Training assessments at regular intervals could provide a "snapshot" look at current operating conditions. Assessments are the only opportunity for management to cite positive performances in process tasks. These assessments could also expose gaps (discrepancies or deficiencies) in task performance related to either display conditions (analog or digital) or behaviors related to the operations tasks. The discovered gaps could then be categorized as either deficiencies or discrepancies in operator task performance. Deficiencies require further investigation and usually more detailed training and performance assessment. Discrepancies usually only require "refresher" type training or task reviews.

It is recognized that training resources and time allotments are not always convenient in an operating atmosphere and therefore segmented modules may provide the most effective approach. For the preceding reasons it was recommended that those persons who work as 
temporary or "fill-in" operators be trained more frequently in all cross-functional operator capacities. As new process automation is introduced into the operational environment, all affected operators should be frequently trained.

\section{$\underline{\text { Recommendations for Further Research }}$}

To achieve a deeper understanding of the effects safety incidents with regard to display instrumentation technologies, a broader communication level needs to be established between the various levels and functions of industry. Within these communications levels, behavioral patterns and process operational functions also need to be assessed from the chemical industry and equipment manufacture perspective so that guidelines and boundaries can be established. Control of processes is the control of boundaries.

In perusing further research in the field of safety incident causes and more particularly where safety records are to be examined, it must be understood by the researcher that there is and will be a natural reluctance to make these types of records available to outside sources. Manufacturers regard these records as "Recorded Failures" within their programs and therefore are not proud of the documentation. The stigma and the underlying implied liability associated publishing safety incident records in a detailed format are formidable and will be a barrier to the researcher. The Bureau of Labor Statistics does, however, publish incident rates in general categories as well as fatality reports that list the company, location, and number of fatalities associated with the incident and brief description.

As found with this research, the group subjects records become more complete within a time frame of the last 8 to 14 years. Records previous to 1985 are not available at the level of detail that would allow for complete examination and analysis. 
Specific recommendations for further research include:

1. The examination of behavioral patterns and frequencies within the chemical industry's control room operators as they relate to patterns affecting the decision making process that may have an impact on safety incident rate.

2. The investigation of industrial events from previous incident records for industries associated with the chemical industry such as pharmaceutical, agricultural, and petroleum to determine transitional impacts of control automation and display indicators to the safety incidence rate.

3. The experimentation, documentation, and analysis of mix display formats for control room operators in the chemical industry. The suggested methodology for this proposed study would be a direct observation or an insitu arrangement Single Case $\mathrm{ABAB}$ design due to ethical considerations.

4. A final suggested research would be that of investigating the extent or to what level current instrumentation manufacturers and suppliers assess their product viability prior to making it available to industry. 


\section{Bibliography}

Barrett, B., Wickens, C., (1988). Display proximity in multicue information integration: The benefit of boxes. Human Factors, Vol. 29, 170-195.

Belke, J., (2000). Chemical accident risks in United States industry: A preliminary analysis of accident risk data from United States hazardous chemical facilities. Washington, D.C.: United States Environmental Protection Agency.

Boles, D., \& Wickens, C., (1987). Display formatting in information integration and nonintegration tasks. Human Factors, Vol. 29, 395-406.

Bowman, D. \& Hodges, L. (1999). Formalizing the design, evaluation, and application of interaction techniques for immersive virtual environments. Journal of Visual Language and Computing, Vol. 10, 37-53.

Bureau of Labor Statistics, BLS Report 1990, [On-Line]: http//www.bls.gov.

Carswell, C., \& Wickens, C., (1987). Information and object display: An interaction of task demands and displays superiority. Ergonomics, Vol. 30, 511-528.

Considine, D. (1991). Process/industrial instruments and controls. Portland, OR: Book News.

Cook, R., Woods, D., \& Howie, M., (1990). The natural history of introducing new information technology into a dynamic high-risk environment. Proceedings of the Human Factors Society, $34^{\text {th }}$ Annual Meeting.

Dick, W., Cary, L., (1996). The Systematic Design of Instruction (4 ${ }^{\text {th }}$ ed.). New York: HarperCollins.

Fantino, E., (1998). Behavior analysis and decision making. Journal of The Experimental Analysis of Behavior. San Diego: Academic Press. 
Farrell, P.S.E., (1999). Human information processing -- Research; information the mathematical models -- Usage Information science; Mathematical modeling. Human Factors, Vol. 41, 2.

Hanson, R., Payne, D., Shively, R., \& Kantowitz, B., (1981). Process control simulation research in monitoring analog and digital displays. Proceedings of the Human Factors Society $25^{\text {th }}$ Annual Meeting. 154-158. Santa Monica, CA: Human Factors and Ergonomics Society.

Hollenagel, E., (2001). Accident Analysis And "Human Error”. [On-Line]: Http//www.ida.liu.se/ eriho/EH_AccidentAnalysisAndHE.htm.

Hollenagel, E. \& Cacciabue, P. (1999). Cognition, Technology And Work: An Introduction. Vol. 1, Issue 1, 1-6, London: Springer-Verlag.

Hutchins, E. (1990). The technology of team navigation. In Galegher, J., Kraut, R., \& Egido, C., (Eds.), Intellectual teamwork: Social and technological Foundations of cooperative work, Hillsdale, New Jersey: Erlbaum Associates.

Kantowitz, B., (1981). Interfacing information processing and engineering psychology. Human performance and productivity. Hillsdale, New Jersey: Erlbaum Associates.

Kantowitz, B., \& Sorkin, R., (1983). Human factors: Understanding people-system relationships. New York: John Wiley and Sons.

Kragt, H., (1983). Operator tasks and annunciator systems. Eindhoven, Holland: Eindhoven University of Technology.

Kazdin, A., (1982). Single-case research designs. New York, NY: Oxford University Press.

Keller, P., (1997). Electronic display measurement: Concepts, techniques, and instrumentation. New York, NY: John Wiley and Sons. 
Kleindorfer,P., Feldman, H., \& Lowe, R., (2000). Accident Epidemiology and the United States Chemical Industry: Preliminary Results from Risk Management Program. Information. Working Paper 00-01-15. State College, Pennsylvania: Center for Risk Management and Decision Processes, The Wharton School, University of Pennsylvania. MacDonald, L. (Ed.) \& Lowe, A. (Ed.). (1997). Display systems: Design and applications (Wiley Sid Series in Display Technology). New York, NY: John Wiley and Sons.

Mullet, K. \& Sano, D. (1994). Designing visual interfaces: Communication oriented techniques. New York, NY: Prentice-Hall.

Multer, J., Rudich, R., \& Yearwood, K. (1998). Human factors guidelines for locomotive cabs. U.S. Department of Transportation: John A Volpe National Transportation Systems Center, DOT-VNTSC-FRA-98-8.

Murnaw, R., Roth, E., Vicente, K., \& Burns, C., (2000). There is more to monitoring a nuclear power plant than meets the eye. Human Factors Vol. 42, 1, 36.

National Safety Council. (1999). Injury Facts. Washington, D.C.: National Safety Council.

Payne, V. \& Lang, D., (1995). Mixed versus pure display format in integration and nonintegration visual display monitoring. Human Factors Vol. 37, 3, 507.

Pedersen, R. \& May, M. (1999). Visualization in process control. Human Factors and Ergonomics in Manufacturing, Vol 3, 267-276.

Pedersen , R. \& Lind, M., (1999). Conceptual design of industrial process displays. Ergonomics. Vol. 42, 11, 1531-1548.

Pew, R., (1969). The speed-accuracy operating characteristic. Acta Psychologica, Vol. 30, 16- 26. 
Poje, G., Rosenthal, I. \& Taylor, A., (2001). United States Chemical Safety and Hazard Investigation Board, Who We Are?. [On line]: info@csb.gov.

Occupational Safety and Health Administration (2002). 29 CFR 1904 Recordkeeping. [On Line]: http://www.osha/pls/oshaweb/owadisp.show_document?p_table=standards\&p_iu $=$ 12805\&p_text_version=FALSE.

Rachlin, H., (1989). Judgement, decision, and choice: A cognitive/behavioral synthesis. New York, NY: Freeman Press.

Rasmussen, J., (1986). Information processing and human-machine interaction: An approach to cognitive engineering. New York, NY: Elsevier Science Publishing Co., Inc.

Rasmussen, J., Pejtersen, A.M. \& Goodstine, L.P., (1994). Cognitive systems engineering. New York, NY: John Wiley and Sons.

Roth, E., Bennett, K., Woods, D. (1987). Human interaction with “intelligent” machine. International Journal of Man-Machine Studies. V 27 :479-525.

Shea, G., (1994). Managing older workers. Menlo Park California: Crisp Publications Inc. Tufte, E., (1997). Visual explanations: Images and quantities, evidence and narrative. New York, NY: Graphics Press.

Tullis, T., (1980). Human performance of graphic and textual CRT displays of diagnostic data. Proceedings of the Human Factors Society, 310-311.

Twenty-nine (29) Code of Federal Regulations (1970). Public Law 91-596.

United States Chemical Safety and Hazard Board (1990). About. [On Line]: http://www.chemsafety.gov/about/who.htm.

Wickens, C. D. (1980). The structure of attentional resources. Attention and Performance. VIII, 233-257. Hillsdale, NJ: Erlbaum. 
Wickens, C. D. (1984). Processing resources in attention. Varieties of Attention. 63-102.

New York: Academic Press.

Wickens, C. D., (1992). Engineering psychology and human performance ( $2^{\text {nd }}$ ed.). New York: Harper Collins.

Wheeler, D. \& Chambers, D., (1992). Understanding statistical process control. New York: SPC Press. 


\section{Appendix A}

\section{Analog/Digital Display Gauge Layout}

Figure A.01 illustrates differences in analog and digital gauges. The analog gauges at the top represent a temperature gauge and a common compass respectively. The small digital display gauges represent digital displays. Both types of gauges are providing the same information for the type represented. Analog display gauges provide a spacial reference to data before and after the indicated data. The digital displays provide only the indicated data with no reference to the range above and below the current indication.

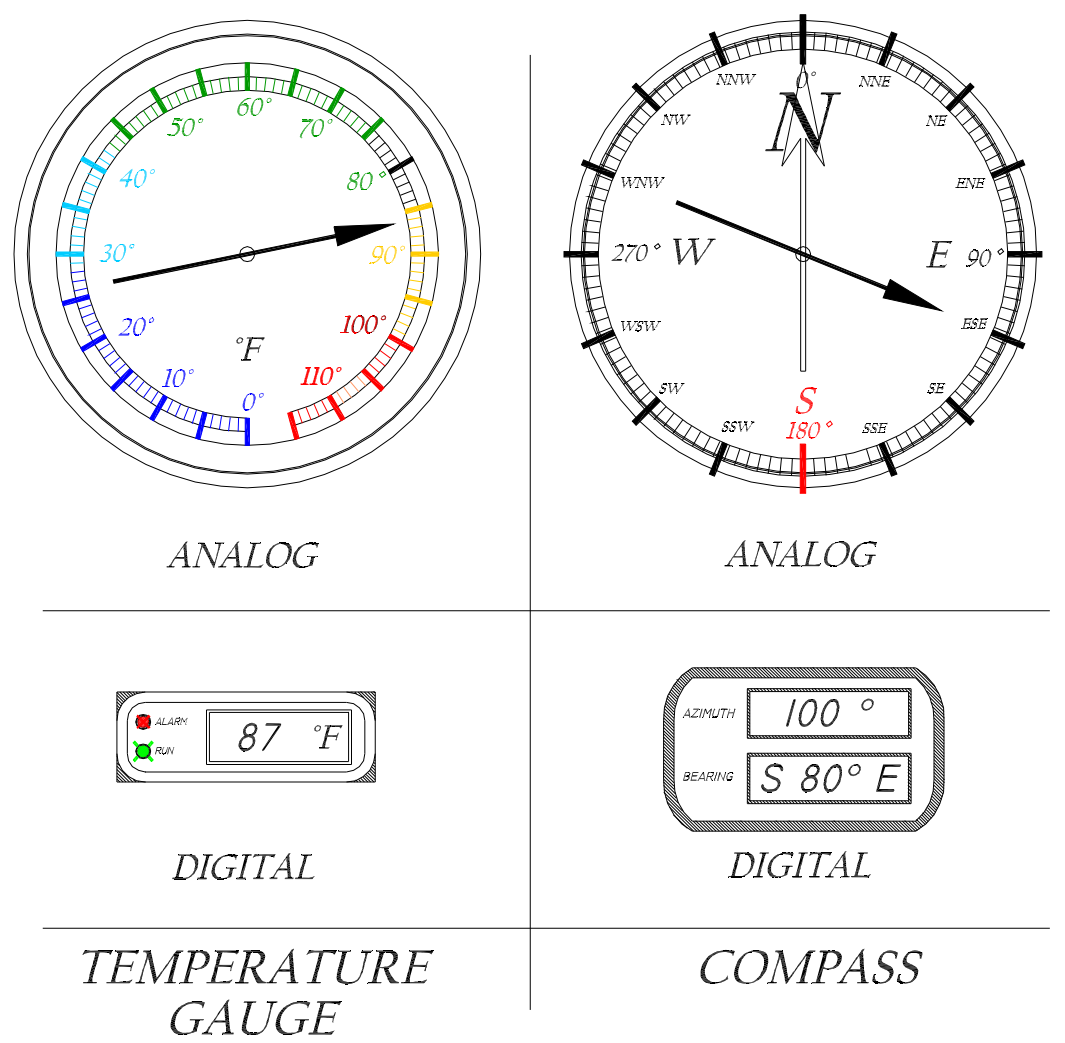

Figure A.01. Gauge Examples 


\section{Appendix B}

\section{Data Gathering}

The Data collection form provided a condensed reference to events recorded in the event reports at the subject facilities. The form was designed so that additional yeas could be added and specific event dates could easily be linked to the specific entries found in the facility data logs. The sequential event reference number in "Column 2" was the same sequence number assigned in the subject facility's log. This entry allowed quick reference to specific events during questions sessions where event clarification was necessary.

The event cause and follow-up training entries provided a snapshot of the level of detail and rememdiation that existed within the facility. This set of data also aided in categorizing the potential impact of the event or seriousness of the event by noting training types such as "Reviewed production sequences, Safety refresher, Hazardous material release talk, etc. 


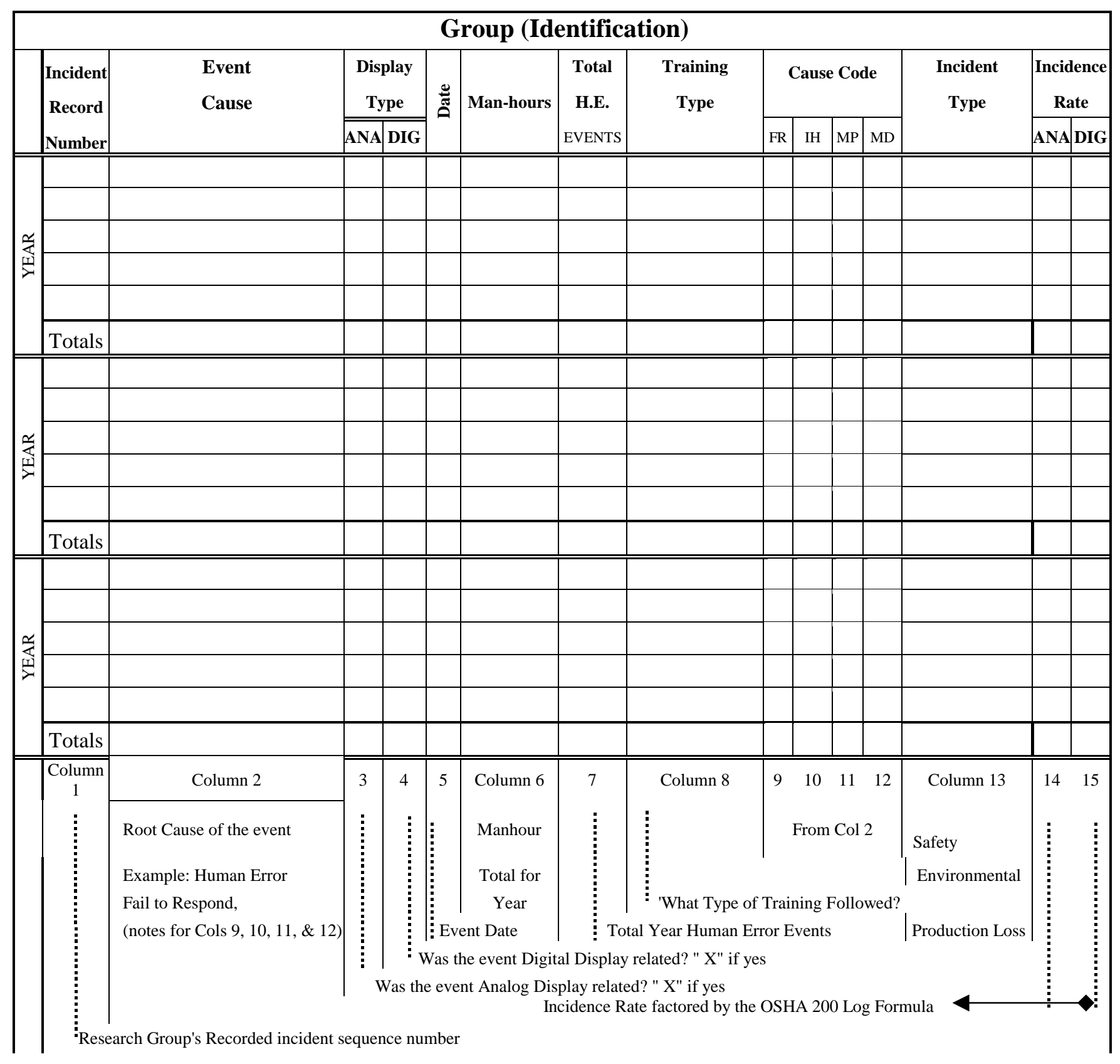

Figure B.01. Data Collection Form 